\section{Estudo de caso do desempenho de estanqueidade à água de argamassas e hidrorrepelentes - Parte I}

\author{
Case study of performance evaluation of \\ watertight of mortars and water \\ repellents - Part I
}

Thiana Dias Herrmann ${ }^{1}$, Gihad Mohamad ${ }^{1}$, Rogério Cattelan Antocheves de Lima ${ }^{1}$, Almir Barros da Silva Santos Neto ", André Lübeck ${ }^{1}$

${ }^{1,}$ Universidade Federal de Santa Maria - UFSM - Avenida Roraima, Centro de Tecnologia, Santa Maria, RS, Brasil. e-mail: thianadh@gmail.com, gihad.civil@gmail.com,rogerio@ufsm.br, almir.neto@ufsm.br, andrelubeck@gmail.com

\title{
RESUMO
}

Um dos agentes desencadeadores de manifestações patológicas em edificações é o ingresso de fluídos e sais em fachadas degradadas pela ausência de manutenção ao longo de sua vida útil. O presente estudo avalia o desempenho de estanqueidade à água de oito revestimentos argamassados, sendo dois dosados em obra e seis industrializados, e de quatro revestimentos hidrorrepelentes formadores de película, utilizados para a recuperação de fachadas degradadas pela ação da umidade. Foram realizados ensaios in loco, em uma fachada degradada pela umidade na cidade de Santa Maria/RS, de permeabilidade à água líquida, empírico de absorção e evaporação da água, de termografia infravermelha e de resistência de aderência à tração. Concluiu-se que os revestimentos hidrorrepelentes apresentaram maior eficácia de estanqueidade à água em relação aos revestimentos argamassados, quando utilizados na recuperação de fachadas degradadas pela umidade.

Palavras-chave: Desempenho à estanqueidade; Recuperação de fachadas; Umidade.

\section{ABSTRACT}

One of the agents that trigger pathological manifestations in buildings is the entrance of fluids and salts into facades degraded by the absence of maintenance throughout their useful life. The present study evaluates the watertight performance of eight mortar coatings, two of which are dosed in construction and seven industrial-ized, and four film-forming water repellent coatings used for the recovery of humidity degraded facades. In situ tests were carried out on a facade degraded by humidity in the city of Santa Maria/RS, permeability to liquid water, empirical absorption and evaporation of water, infrared thermography, and tensile adhesion strength. It was concluded that water repellent coatings presented greater efficiency of watertight compared to mortar coatings, when used for the recovery of humidity degraded facades.

Keywords: Performance to watertight. Recovery of façades. Humidity.

\section{INTRODUÇÃO}

Em edifícios, as fachadas exercem grande responsabilidade de manter a durabilidade dos planos verticais, protegendo-os contra os agentes agressivos mantendo o desempenho ao longo da vida útil da edificação. A durabilidade do edifício e de seus sistemas é uma exigência econômica, estando associada diretamente ao custo global do bem imóvel. Extingue-se a durabilidade da edificação ou de um dos seus sistemas componentes, quando não mais cumprem as funções que lhe foram impostas, podendo ser pela perda de desempenho ocorrido pela degradação ou pela redução da vida útil [1]. A forma pelo qual um revestimento de fachada reage à umidade é um parâmetro relevante em termos de desempenho [2].

O estudo da degradação das fachadas no Brasil, infelizmente, ainda é alocado em segundo plano nas investigações científicas, sendo que a falta de ações adequadas de manutenção é uma das razões que levam à 
degradação atual e ao próprio envelhecimento precoce dos elementos de vedação e revestimento [3-4].

Discorrendo-se sobre as fachadas, é fundamental o estudo de revestimentos que, ao entrarem em contato com a umidade, evitem sua entrada no material. De acordo com Salomão [5], para a proteção ou tratamento das edificações à ação da umidade é preciso escolher um método baseado em análises delineadas do elemento a ser tratado e de seus materiais, da condição de exposição e, também, dos mecanismos de transporte de umidade. Podem-se utilizar diferentes produtos impermeabilizantes disponíveis no mercado, contudo, as suas propriedades geralmente não são informadas (composição química ou mecanismo de ação), revelando que há uma carência de informações técnicas sobre os produtos de ação impermeabilizante. Diante disto, a pesquisa foi dividida em duas etapas, sendo a primeira descrita neste artigo. Com a finalidade de avaliar as manifestações patológicas em revestimentos de fachada e sua recuperação, esta pesquisa comparou diferentes revestimentos quanto ao seu desempenho de estanqueidade à água e aderência à tração. Para tanto, selecionou-se revestimentos em argamassa de recuperação profunda com a substituição total do revestimento, e o emprego de películas hidrorrepelentes e argamassas de recuperação superficial, todos disponíveis no mercado da construção civil, os quais foram aplicados em uma fachada degradada por aproximadamente 20 anos, com orientação solar sul, na cidade de Santa Maria/RS. Foram avaliadas formas de recuperação dessa fachada degradada por meio da avaliação do desempenho de estanqueidade à água de diferentes produtos de revestimento ou repelentes, sendo oito revestimentos argamassados, destes dois dosados em obra e seis industrializados, e de quatro revestimentos hidrorrepelentes formadores de película.

\subsection{A água no edifício}

O fluxo de água nos materiais de construção das edificações, principalmente nas estruturas de alvenaria, é considerado um fator limitante para a durabilidade [6]. Os altos níveis de umidade prejudicam o edifício, tornando a penetração da água em materiais de construção porosos um método essencial na análise da durabilidade de qualquer sistema da edificação [7]. No caso das fachadas, conforme Hall e Kalimeris [8], a chuva quando em contato com a superfície porosa, é absorvida em grande parte pelo material, sendo imobilizada temporariamente por variações dimensionais e liberada posteriormente por evaporação, produzindo retrações. No caso de superfícies impermeáveis, toda a água da chuva flui livremente pela superfície, sem ingressar no material. Deste modo, a análise do movimento da água no edifício deve abranger tanto a fase líquida da água, quanto o transporte e sua evaporação. Praticamente toda a água absorvida nos materiais de construção deve, posteriormente, ser liberada por evaporação. Ou seja, a evaporação desempenha uma função primordial no controle dos balanços de água e taxas de troca de água entre ambiente e estrutura [9].

\subsection{Desempenho à estanqueidade à água de fachadas}

É importante minimizar a degradação proveniente da ação da umidade na conservação de edifícios, pois esta pode ocasionar alterações estéticas nos elementos afetados, bem como o surgimento de eflorescência, colonização biológica, manchas, entre outras manifestações patológicas, ou ainda ocasionar modificações estruturais por meio da manifestação de fissuras ou desplacamentos [10]. Nas fachadas, de acordo com Chew e Tan [11], a degradação decorre sobretudo da ação conjunta da chuva, vento, variações térmicas e poluentes atmosféricos e biológicos, quando a água da chuva escoa por meio da superfície vertical, lavando a fachada e depositando agentes agressivos. Para Ge et al. [12] a chuva associada ao vento é a principal fonte de umidade que afeta o desempenho higrotérmico e a durabilidade das fachadas, sendo que a quantidade e distribuição é afetada pela velocidade e direção do vento, intensidade da chuva, ângulo do vento, geometria do prédio, localização das fachadas e topografia do entorno.

A estanqueidade à água é um dos requisitos fundamentais de durabilidade de fachadas. A norma brasileira NBR 15575-4 [13] determina que os sistemas de vedações verticais externos precisam ser estanques à água advinda da incidência de chuvas ou de outras fontes. Não devem resultar em infiltrações que proporcionem borrifamentos, escorrimentos ou formação de gotas de água aderentes na face interna da fachada [14-15].

Uma das funções almejadas das paredes externas é proteger as partes internas e sensíveis da construção do clima externo. As fachadas atuam como uma barreira contra as agressões externas, estabelecendo simultaneamente um meio de comunicação entre o interior e o exterior. Para avaliar o desempenho de uma fachada, é necessário identificar seus componentes e as agressões que irão afetá-la.

A presença de água nas fachadas é admissível, mas a partir de um determinado nível passa a ser prejudicial aos seus componentes, afetando a durabilidade do edifício. Em revestimentos de fachada, o estado limite de durabilidade pode ocorrer quando há perda de aderência que se manifesta, por exemplo, através de desplacamentos. Mas antes de atingir este estado, o revestimento exibe um padrão de degradação identificável e bem definido ao longo do tempo. Primeiro se manifestam manchas de sujeira de pequena gravidade, em 
seguida há aumento e agravamento das áreas atingidas, há manifestação de fissuras, ocorre a sobreposição de anomalias, até resultar na perda de aderência do revestimento [16].

\subsection{Sistemas de revestimentos}

Esse trabalho trata de um estudo de caso onde foram avaliadas diferentes possibilidades de revestimentos para recuperação superficial (hidrorrepelentes e argamassas) ou profunda (argamassas tradicionais ou modificadas com aditivos impermeabilizantes) de uma fachada degradada por aproximadamente 20 anos, com orientação Sul, em uma edificação localizada na cidade de Santa Maria /RS. Grande parte dos estudos encontrados na literatura não tratam especificamente dos tratamentos aplicados nesta pesquisa, pois foram escolhidos de acordo com as práticas disponíveis no mercado da construção civil local e regional. Os objetivos destas análises foram comparar as características físicas e mecânicas do reboco médio tradicional, definido por AP-IND-RM, com as demais opções de sistema de revestimento. Não foram encontradas pesquisas comparativas utilizando produtos e técnicas semelhantes aos empregados nesse estudo. Por exemplo, um dos revestimentos testados foi uma argamassa colante do tipo AC-III para simples correções das fachadas, sendo uma prática empregada na região para corrigir falhas e uniformizar os revestimentos degradados para posterior pintura direta.

Foram empregados oito tipos de revestimentos argamassados de acordo com as práticas construtivas locais e quatro sistemas de proteção de fachadas pela ação hidrorrepelente. Os revestimentos de argamassa avaliados nesta pesquisa são apresentados na Tabela 1 e foram classificados como materiais cimentícios para impermeabilização, segundo a norma NBR 9575 [17]. A exceção foi o revestimento de argamassa AP-INDRM, sem ação hidrofugante e que serviu apenas como referência comparativa para o desempenho dos demais revestimentos e hidrorrepelentes com relação à ação da umidade. Todas as informações das características, composição e tipo de recuperação estão descritas na Tabela 1, e foram retirados dos catálogos técnicos fornecidos pelos fabricantes dos produtos.

Tabela 1: Discriminação dos revestimentos de argamassa.

\begin{tabular}{|c|l|l|l|l|}
\hline \multicolumn{1}{|c|}{ TIPO } & \multicolumn{1}{|c|}{ DEFINIÇÃo } & \multicolumn{1}{c|}{ COMPOSIÇÃo } & $\begin{array}{l}\text { CARACTERÍSTICAS FORNECIDAS } \\
\text { PELO FABRICANTE }\end{array}$ & $\begin{array}{c}\text { TIPO DE } \\
\text { RECUPE- } \\
\text { RAÇÃO }\end{array}$ \\
\hline \multirow{2}{*}{ AS-PSP } & $\begin{array}{l}\text { Argamassa industriali- } \\
\text { zada: colante Piso so- } \\
\text { brepiso. }\end{array}$ & $\begin{array}{l}\text { Cimento Portland, } \\
\text { agregados minerais } \\
\text { selecionados e aditi- } \\
\text { vos químicos. }\end{array}$ & $\begin{array}{l}\text { Argamassa leve de excelente trabalha- } \\
\text { bilidade, ideal para assentamento de } \\
\text { revestimentos cerâmicos, porcelanatos, } \\
\text { pedras rústicas em áreas internas e ex- } \\
\text { ternas em pisos e paredes; Aplicação de } \\
\text { sobreposição de revestimentos cerâmi- } \\
\text { cos antigos. }\end{array}$ & Superficial \\
\hline AS-ACIII & $\begin{array}{l}\text { Argamassa industriali- } \\
\text { zada: colante AC III. }\end{array}$ & $\begin{array}{l}\text { Cimento, areia quar- } \\
\text { tzosa, aditivos espe- } \\
\text { ciais e polímeros. }\end{array}$ & $\begin{array}{l}\text { Argamassa colante de uso interno ou } \\
\text { externo de alta adesividade e flexibili- } \\
\text { concreto, cerâmicas em piscinas aque- } \\
\text { cidas ou não e saunas, piso de tráfego } \\
\text { intenso. }\end{array}$ & Superficial \\
\hline
\end{tabular}

(conclusão)

\begin{tabular}{|c|c|c|c|c|}
\hline AS-PB & $\begin{array}{l}\text { Argamassa industria- } \\
\text { lizada: polimérica } \\
\text { bicomponente. }\end{array}$ & $\begin{array}{l}\text { Pó: Resina melami- } \\
\text { na-formaldeído, } \\
\text { resina melamina- } \\
\text { formaldeído con- } \\
\text { densada, cimento, } \\
\text { agregados minerais } \\
\text { e aditivos especiais. } \\
\text { Líquido: Copolíme- } \\
\text { ro compatível com } \\
\text { cimento. }\end{array}$ & $\begin{array}{l}\text { Revestimento modificado com políme- } \\
\text { ros, impermeável e de alta aderência. }\end{array}$ & Superficial \\
\hline
\end{tabular}




\begin{tabular}{|c|c|c|c|c|}
\hline $\begin{array}{l}\text { AP-IND- } \\
\text { RM }\end{array}$ & $\begin{array}{l}\text { Argamassa industria- } \\
\text { lizada: revestimento. }\end{array}$ & $\begin{array}{l}\text { Cal hidratada CH-II, } \\
\text { cimento Portland } \\
\text { CPII-Z-32, areia } \\
\text { calcária e classifi- } \\
\text { cada e fíler mineral. }\end{array}$ & Argamassa de reboco médio. & Profunda \\
\hline AP-DO-L & $\begin{array}{l}\text { Argamassa tradicio- } \\
\text { nal dosada em obra: } \\
\text { revestimento. }\end{array}$ & $\begin{array}{l}\text { Cimento, areia mé- } \\
\text { dia e aditivo líquido } \\
\text { composto de silica- } \\
\text { tos. }\end{array}$ & $\begin{array}{l}\text { Aditivo de altíssima capacidade de } \\
\text { redução da permeabilidade de concretos } \\
\text { e argamassas por hidrofugação do sis- } \\
\text { tema capilar. Permite as trocas gasosas } \\
\text { dos materiais, mantendo os ambientes } \\
\text { salubres. }\end{array}$ & Profunda \\
\hline AP-DO-P & $\begin{array}{l}\text { Argamassa tradicio- } \\
\text { nal dosada em obra: } \\
\text { revestimento. }\end{array}$ & $\begin{array}{l}\text { Cimento, areia e } \\
\text { aditivo em pó com- } \\
\text { posto de cargas } \\
\text { minerais e aditivos } \\
\text { especiais. }\end{array}$ & $\begin{array}{l}\text { Aditivo que possui propriedade hidror- } \\
\text { repelente, com alto poder de aderência, } \\
\text { aumentando a resistência. Melhora a } \\
\text { trabalhabilidade e elimina as fissuras de } \\
\text { retração no reboco. Elimina a utilização } \\
\text { da cal nas massas e dispensa o uso de } \\
\text { outros aditivos. }\end{array}$ & Profunda \\
\hline AP-IND-I1 & $\begin{array}{l}\text { Argamassa industria- } \\
\text { lizada: revestimento. }\end{array}$ & $\begin{array}{l}\text { Areia calcária, areia } \\
\text { quartzosa, agrega- } \\
\text { dos leves, cal hidra- } \\
\text { tada, cimento Por- } \\
\text { tland e aditivos. }\end{array}$ & $\begin{array}{l}\text { Argamassa impermeável para correção } \\
\text { ou prevenção de proteção de paredes e } \\
\text { tetos com problemas de umidade. }\end{array}$ & Profunda \\
\hline AP-IND-I2 & $\begin{array}{l}\text { Argamassa industria- } \\
\text { lizada: revestimento }\end{array}$ & $\begin{array}{l}\text { Cimento, agregados } \\
\text { minerais, aditivos } \\
\text { especiais e aditivos } \\
\text { impermeáveis. }\end{array}$ & $\begin{array}{l}\text { Argamassa pronta para impermeabili- } \\
\text { zação e recuperação. }\end{array}$ & Profunda \\
\hline
\end{tabular}

Os revestimentos formadores de película do tipo hidrorrepelentes avaliados nesta pesquisa, são classificados de acordo com a NBR 9575 [17] como membrana para impermeabilização. Na Tabela 2 estão apresentados os hidrorrepelentes empregados com suas respectivas características, conforme os catálogos fornecidos pelos fabricantes.

Tabela 2: Descrição dos revestimentos hidrorrepelentes.

\begin{tabular}{|c|c|c|c|c|}
\hline TIPO & DEFINIÇÃO & COMPOSIÇÃO & $\begin{array}{c}\text { CARACTERÍSTICAS FORNECIDAS PELO } \\
\text { FABRICANTE }\end{array}$ & $\begin{array}{c}\text { TIPO DE } \\
\text { RECUPERAÇÃO }\end{array}$ \\
\hline HIDRO1 & $\begin{array}{l}\text { Hidrorrepelente: } \\
\text { formador de pelí- } \\
\text { cula. }\end{array}$ & $\begin{array}{l}\text { Água, copolímero } \\
\text { acrílico, solventes } \\
\text { orgânicos, pig- } \\
\text { mento inorgânico. }\end{array}$ & $\begin{array}{l}\text { Possui propriedades elásticas e protege a } \\
\text { fachada da água da chuva e da ação direta } \\
\text { do sol, e impede a penetração da umidade } \\
\text { evitando a formação de manchas de bolores } \\
\text { ou fungos. Forma uma membrana elástica e } \\
\text { impermeável. Ótima barreira aos agentes } \\
\text { agressores oriundos da atmosfera. Mantém } \\
\text { as propriedades a baixas temperatura e } \\
\text { pode ser pigmentado. }\end{array}$ & Superficial \\
\hline HIDRO2 & $\begin{array}{l}\text { Hidrorrepelente: } \\
\text { formador de pelí- } \\
\text { cula. }\end{array}$ & $\begin{array}{l}\text { Agregados mine- } \\
\text { rais, copolímero } \\
\text { acrílico em dis- } \\
\text { persão aquosa. }\end{array}$ & $\begin{array}{l}\text { Oferece grande aderência e durabilidade, é } \\
\text { indicado para impermeabilizar paredes } \\
\text { externas sujeitas a chuva. É flexível e elás- } \\
\text { tico, e pode ser pigmentado. }\end{array}$ & Superficial \\
\hline
\end{tabular}




\begin{tabular}{|l|l|l|l|l|}
\hline HIDRO3 & $\begin{array}{l}\text { Hidrorrepelente: } \\
\text { formador de pelí- } \\
\text { cula. }\end{array}$ & $\begin{array}{l}\text { Impermeabilizan- } \\
\text { te à base de água, } \\
\text { composto de resi- } \\
\text { nas acrílicas, } \\
\text { areia quartzosa. }\end{array}$ & $\begin{array}{l}\text { Impermeabilizante acrílico que protege } \\
\text { contra a umidade e desgastes provocados } \\
\text { pela ação do tempo ou da maresia. Acom- } \\
\text { panha o movimento de expansão e retração } \\
\text { que ocorre na parede devido às variações } \\
\text { de temperatura. }\end{array}$ & Superficial \\
\hline HIDRO4 & $\begin{array}{l}\text { Hidrorrepelente: } \\
\text { formador de pelí- } \\
\text { cula. }\end{array}$ & $\begin{array}{l}\text { Impermeabilizan- } \\
\text { te à base de água, } \\
\text { composto de resi- } \\
\text { nas acrílicas. }\end{array}$ & $\begin{array}{l}\text { Possui grande elasticidade, acompanhando } \\
\text { o movimento de dilatação e retração de } \\
\text { paredes e lajes, conforme a variação de } \\
\text { temperatura. Material com características } \\
\text { que possibilita a penetração nas fissuras e } \\
\text { rachaduras. }\end{array}$ & Superficial \\
\hline
\end{tabular}

\section{MATERIAIS E MÉTODOS}

\subsection{Estudo de caso}

Na Figura 1 visualiza-se a fachada sul da edificação, com degradação perceptível, onde foram realizadas as aplicações dos diferentes sistemas de revestimentos. Primeiramente, foram identificadas as principais manifestações patológicas existentes, como o destacamento da pintura, esfarelamento do reboco e degradação biológica, sendo os agentes causadores destas manifestações a umidade, proveniente da precipitação da água da chuva e das trocas de vapor entre a face externa e interna, a condensação de água na superfície e a falta de manutenção preventiva ou corretiva do revestimento original.

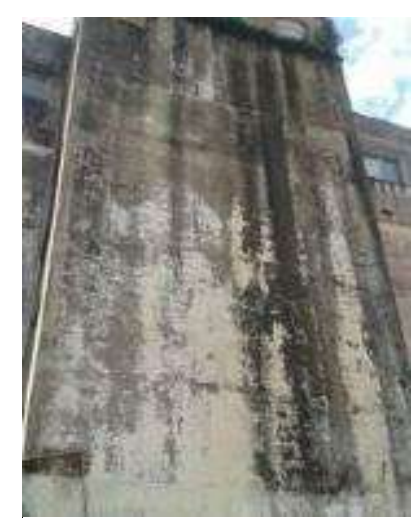

Figura 1: Fachada utilizada para o estudo.

\subsection{Revestimentos empregados}

A partir do diagnóstico da origem das anomalias existentes na fachada em estudo, buscaram-se alternativas de revestimentos que permitissem a recuperação da fachada para avaliar comparativamente os resultados quanto à permeabilidade à água e aderência. Além disso, investigaram-se as práticas construtivas locais e regionais que foram utilizadas com o intuito de corrigir os defeitos superficiais produzidos pelo desgaste, para posterior pintura da edificação. Optou-se por uma fachada já degradada, que permitisse avaliar o desempenho quanto à permeabilidade a água líquida pelo método do cachimbo, a correlação entre a rugosidade superficial do revestimento e a absorção inicial de água da superfície, por meio de um procedimento de teste desenvolvido pelos autores denominado de "método empírico", a avaliação da temperatura superficial por termografia e a resistência de aderência à tração do revestimento. Os revestimentos avaliados foram divididos em dois grupos: revestimentos argamassados com a substituição total do reboco presente (ditos de recuperação profunda), revestimentos hidrorrepelentes e argamassas aplicados na superfície tratada (ditos de recuperação superficial). No total foram avaliados doze sistemas de revestimentos, sendo oito do tipo argamassados e quatro do tipo hidrorrepelentes, como descritos nas Tabelas 1 e 2 . 


\subsection{Tratamento da fachada e limpeza superficial}

Inicialmente foi realizada a limpeza química da fachada utilizando hipoclorito de sódio em uma concentração de 5\%, a fim de remover os microrganismos existentes. Em seguida, foi realizado o hidrojateamento com água sob pressão para eliminar resquícios de pintura, oleosidades e sujeiras impregnadas na superfície. Na Figura 2 é exemplificado o processo de limpeza, sendo estas etapas preliminares realizadas para o início da pesquisa baseado na norma NIT 197 [18].

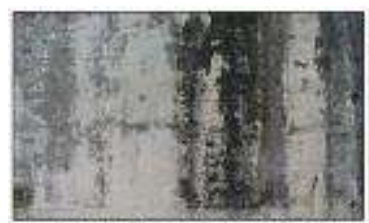

ASPECTO INICLAL DA FACHADA ANTES OA LIMPEZA

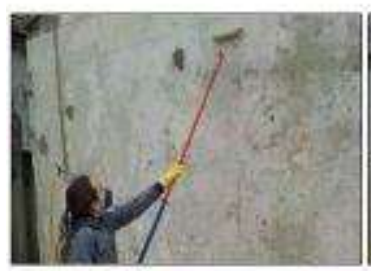

LAVAGEM COM HIPOCLORITO

DE $\$ 00105 \%$

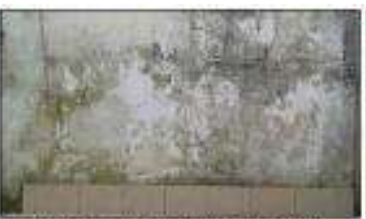

ASPLCTO DA FACHADA APÓS LXARENTO

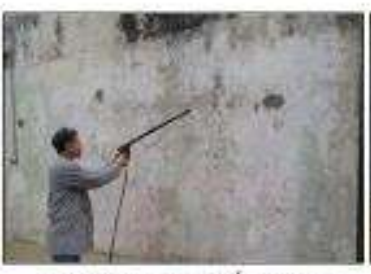

ENXAGUE DOS RESIDUOS DO HIPOCLORITO DE SODIO $5 \%$

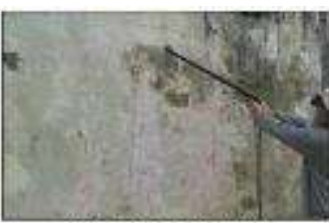

LAVAGEM COM AGUA UTILIZANDO LAVA A MATO OE ALTA PRESSHO

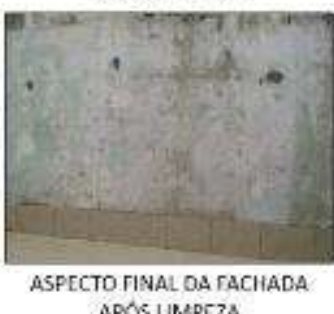

Figura 2: Procedimento de limpeza da fachada.

\subsection{Delimitação da área de aplicação dos revestimentos}

Foram delimitadas áreas para a aplicação dos diferentes tipos de tratamento na fachada. As aplicações dos revestimentos seguiram as técnicas recomendadas pelos fabricantes de cada produto. Na Figura 3 mostram-se as respectivas localizações na fachada de cada um dos sistemas testados, sendo que para cada tipo de revestimento foi utilizado uma área de aproximadamente 1,0 $\mathrm{m}^{2}$. Os rebocos do tipo AP-IND-RM, AP-DO-L, APIND-I1, AP-DO-P e AP-IND-I2, sistemas de recuperação profunda, foram aplicados após a completa retirada do revestimento original.
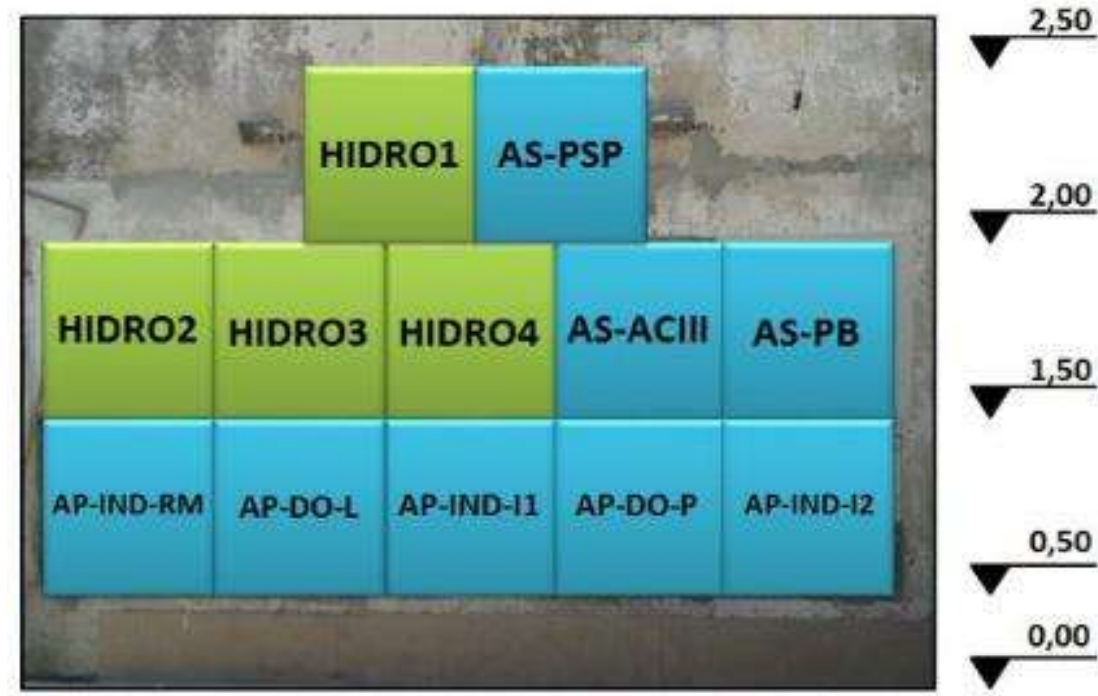

REVESTIMENTO DE ARGAMASSA

REVESTIMENTO HIDRORREPELENTE

Figura 3: Distribuição dos revestimentos na fachada (níveis indicados em metros). 


\subsection{Permeabilidade à água líquida pelo método do cachimbo}

O ensaio de permeabilidade à água líquida se baseou na norma RILEM N ${ }^{0}$ II.4 [19], que visa determinar a capacidade de absorção de água de um revestimento durante um certo período de tempo utilizando o método do cachimbo. As leituras do nível da água no cachimbo são efetuadas em 5, 10, 15, 30 e 60 minutos ou até a água atingir o volume absorvido de $4,0 \mathrm{~cm}^{3}$, para ensaio realizado in loco este tempo pode ser reduzido para 5,10 e $15 \mathrm{~min}$. Foram utilizados seis (6) cachimbos de vidro para cada metro quadrado $\left(1 \mathrm{~m}^{2}\right)$ de revestimento avaliado, os quais foram fixados com silicone e vedados com massa de calafetar. Como os revestimentos possuem propriedades hidrofugantes, a absorção do líquido pelo revestimento é lenta e, deste modo, definiuse por realizar as leituras em 5, 10, 15, 30, 60, 120, 180, 1440 e 2880 minutos. Os cachimbos de vidro foram preenchidos com água até o nível de $4 \mathrm{~cm}^{3}$ e a cada leitura realizada eram novamente preenchidos com água retornando à pressão de $92 \mathrm{~mm}$ na coluna d'água. $\mathrm{O}$ ensaio foi realizado quando as condições ambientais eram de $24 \pm 2^{\circ} \mathrm{C}$ de temperatura ambiente e $60 \pm 5 \%$ de umidade relativa do ar no tempo inicial do ensaio.

Além da representação gráfica dos resultados indicando a quantidade de água absorvida ao longo do tempo, é possível determinar, também, o coeficiente de absorção a partir da equação apresentada pela PROCEQ apud FLORES-COLEN [20]:

$$
\mathrm{C}_{\text {absorção }}=\frac{\mathrm{x} \times 10^{-3}}{\mathrm{~d}^{2} \times\left(\frac{\pi}{4} \times 10^{-6} \times \sqrt{t}\right)}
$$

Onde, $\mathrm{C}_{\mathrm{absorção}}=$ coeficiente de absorção de água da camada superficial $\left(\mathrm{kg} /\left[\mathrm{m}^{2} \cdot \mathrm{x} \cdot \mathrm{h}^{1 / 2}\right]\right) ; \mathrm{x}=$ quantidade de água absorvida $(\mathrm{ml}) ; \mathrm{d}=$ diâmetro da superfície pela qual é feita a absorção da água $(\mathrm{mm}) ; \mathrm{t}=$ tempo da leitura (h).

Na norma ISO 15148 [21] propõe uma equação para a determinação da massa de água absorvida por unidade de área da superfície $\left(\mathrm{kg} / \mathrm{m}^{2}\right)$ :

$$
\mathrm{m}_{\mathrm{abs}}=\mathrm{A} \times \sqrt{t_{\text {rain }}} \times \mathrm{C}_{\mathrm{absorção}}
$$

Onde, $\mathrm{m}_{\mathrm{abs}}=$ absorção de água pela fachada $\left(\mathrm{kg} / \mathrm{m}^{2}\right) ; \mathrm{A}=$ coeficiente de absorção de água da camada superficial $\left(\mathrm{kg} /\left[\mathrm{m}^{2} \cdot \mathrm{x} \cdot \mathrm{h}^{1 / 2}\right]\right) ; \mathrm{t}=$ tempo de ensaio (em horas).

\subsection{Desenvolvimento de um método empírico para avaliação indireta da absorção da água}

Este ensaio, de ordem qualitativa e quantitativa, permite avaliação da absorção de água superficial e o espalhamento da sua mancha devido ao tamanho do agregado e a rugosidade da superfície, a partir da observação visual e medições ao longo do tempo. Para tanto, utiliza-se um conta-gotas com capacidade de no mínimo dois (2) mililitros (ml), cronômetro e trena para a tomada das medidas. Inicialmente analisou-se a absorção de água superficial e em seguida o espalhamento ou manchamento no revestimento. Também, verificou-se o tempo de demora para a evaporação superficial do líquido. Esse procedimento de teste buscou, entre outras questões, simular o escoamento da água da chuva ao longo da parede, avaliar a rugosidade superficial decorrente do tamanho do agregado miúdo e a absorção de água por parte do revestimento.

O procedimento do ensaio consistiu em encher com água um conta-gotas até o nível de $2 \mathrm{ml}$ e, lentamente, no topo do revestimento, permitir a queda da água sob ação da gravidade por um tempo de, aproximadamente, vinte segundos. Este processo foi realizado quatro vezes com espaçamento médio de $20 \mathrm{~cm}$ entre as quedas d'água. Depois da queda, foi registrada a distância “ $d$ ” absorvida de queda d'água desde o topo até a base da mancha e a largura média $(\mathrm{lm})$ do espalhamento de absorção. Registrou-se, também, o tempo (em minutos) que o revestimento levava para evaporar a água absorvida desde o momento de finalização de queda (final dos vinte segundos). Na Figura 4 ilustram-se as etapas de execução do ensaio. 

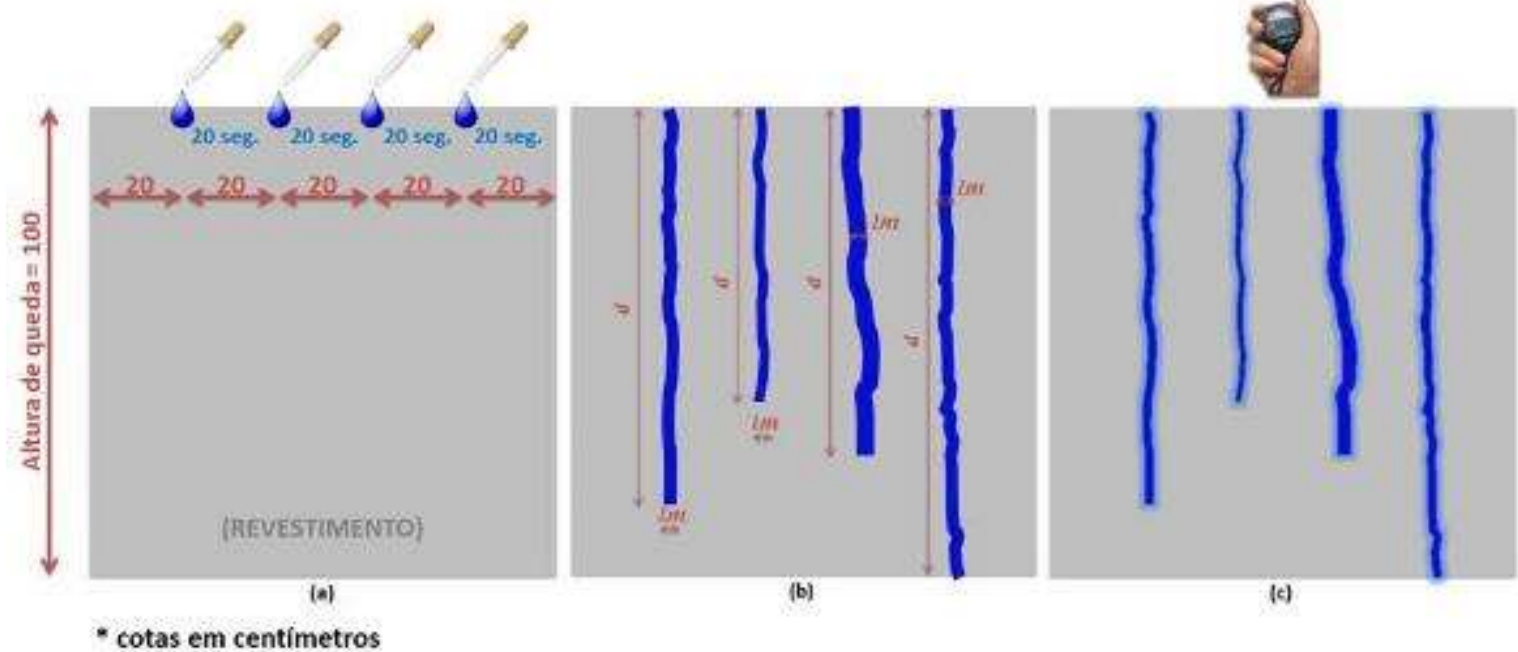

* cotas em centímetros

Figura 4: Etapas do ensaio de absorção e evaporação da água.

A análise qualitativa foi efetuada visualizando o comportamento dos revestimentos em função das quedas de água de maneira essencialmente comparativa, como a forma de queda e o espalhamento lateral devido à absorção da água ao longo da superfície. Já a análise quantitativa foi realizada a partir das médias das medições de altura de queda e espalhamento de absorção, da área de espalhamento da água absorvida e do tempo de evaporação da água. O ensaio foi realizado nos revestimentos quando estes se encontravam na condição "naturalmente seca". Foi possível realizá-lo em todos os revestimentos em um mesmo dia e turno, mantendo as mesmas variáveis e condições iguais para todos os tipos de recuperação, sendo o ensaio realizado aos 28 dias após a aplicação do revestimento.

\subsection{Termografia infravermelha}

A termografia por infravermelho foi empregada para avaliar a temperatura da superfície dos revestimentos a partir das imagens termográficas. Necessitando para isso, utilizar os parâmetros de emissividade, temperatura ambiente, distância à superfície e umidade relativa do ar, para correção dos valores de temperatura registrados com auxílio de um software de análise de imagens termográficas. O ensaio foi executado com base na norma EN 13187 [22]. Para determinar a emissividade dos revestimentos utilizou-se a norma ISO 18434-1 [23], sendo que a temperatura e umidade relativa do ar foram medidas por meio de um termo-higrômetro. A realização do ensaio aconteceu quando os revestimentos se encontravam "naturalmente secos" e após incidência de chuva estando eles "naturalmente úmidos", e com idade de 6 meses de aplicação dos revestimentos. As medições foram efetuadas ao longo do dia, durante a manhã e tarde, com intervalos de aproximadamente 4 horas, avaliando as diferenças de temperatura nas superfícies dos revestimentos em relação à umidade, uma vez que quanto maior a quantidade de água absorvida, menor a temperatura na superfície.

\subsection{Resistência de aderência à tração}

O ensaio de resistência de aderência à tração é de fundamental importância, pois verifica a interação entre as camadas que constituem o revestimento, permitindo obter o valor da tensão máxima de aderência do revestimento, assim como em qual interface do revestimento ocorre a ruptura. A resistência de aderência à tração foi avaliada de acordo com a equação apresentada na NBR 13528 [24], sendo que, conforme a norma, dentre os doze corpos de prova ensaiados, oito devem apresentar valores de resistência de aderência à tração de no mínimo 0,30 MPa para revestimentos de argamassa em paredes externas. A execução deste ensaio ocorreu somente após o final da realização de todos os demais ensaios citados anteriormente.

Com uma furadeira acoplada a uma broca tipo serra-copo de $50 \mathrm{~mm}$ de diâmetro, foram feitos os furos para preparação dos exemplares para extração. Ao todo foram feitos 12 furos distribuídos de forma aleatória, contemplando juntas e blocos. Após a limpeza da superfície, em amostra preparada, foi colada com resina epóxi uma pastilha circular que dispunha de um acoplamento para o equipamento de tração. Posteriormente a estas etapas, foi posicionado o aparelho de arrancamento (dinamômetro de tração) dotado de dispositivo para leitura de carga. Por ser um ensaio mecânico de grande variabilidade, inicialmente, procedeu-se um tratamento estatístico com os resultados obtidos, excluindo os valores espúrios do total de amostras analisadas. Os 
valores espúrios foram determinados a partir da média dos doze corpos de prova e do desvio padrão amostral para cada sistema de revestimento avaliado. Com a distribuição dos valores das médias, desvios padrões e a determinação do intervalo de confiança, foram excluídos os resultados que estavam fora da faixa entre a média mais o desvio padrão e a média menos o desvio padrão. Após a verificação dos valores espúrios, calculou-se uma nova média considerando somente os valores que se encontravam neste intervalo.

\section{RESULTADOS E DISCUSSÕES}

\subsection{Permeabilidade à água líquida pelo método do cachimbo}

Na Figura 5, são apresentados os resultados de permeabilidade à água líquida dos revestimentos argamassados pelo método do cachimbo. Os revestimentos com argamassa de recuperação superficial AS-PSP e ASACIII e o revestimento de argamassa de recuperação profunda AP-DO-L atingiram o limite da absorção à água com um tempo inferior a 180 minutos, onde toda a água contida no cachimbo foi permeada para o interior do revestimento. Já os demais sistemas de revestimentos possibilitaram a avaliação desta propriedade ao longo do tempo de 2880 minutos, ou seja, o fluxo de água para o interior da amostra foi menor em relação aos avaliados anteriormente, demostrando melhor desempenho comparativo quanto a estanqueidade e permeabilidade à água. Na Figura 5 foi destacada e ampliada a área hachurada para permitir uma melhor avaliação dos resultados nos tempos iniciais. Nestas condições pode-se concluir que as argamassas de revestimento de recuperação superficial (AS-PSP e AS-ACIII) e profunda AP-DO-L são mais suscetíveis à fissuração por retração e, por consequência, formação de fissuras por mapeamento superficial do revestimento argamassado.

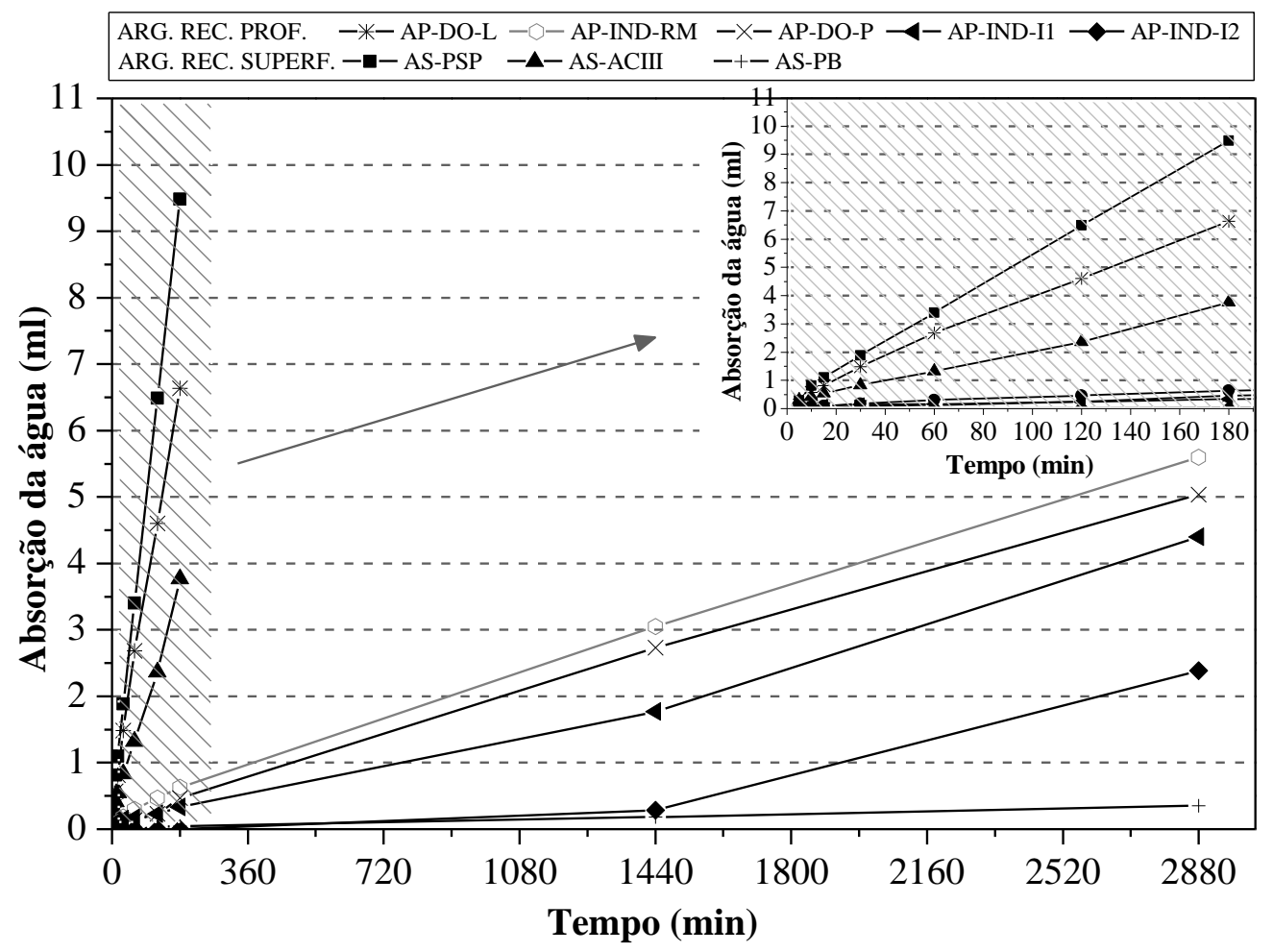

Figura 5: Permeabilidade à água líquida pelo método do cachimbo das argamassas.

A maior parte dos revestimentos de argamassa de recuperação profunda aos 1440 minutos tiveram uma absorção de água líquida de até $3 \mathrm{ml}$, valor este que pode ser considerado pequeno e, portanto, de menor susceptibilidade à fissuração por retração. O revestimento AP-IND-I2 obteve uma absorção de água inferior a $4 \mathrm{ml}$ no tempo limite estabelecido de 2880 minutos, demostrando a sua capacidade, comparativamente aos demais, de impedir a entrada de água no revestimento. Destaca-se que as argamassas de recuperação profunda que apresentaram melhor desempenho foram as industrializadas. A argamassa tradicional produzida em obra (AP-DO-L) absorveu aos 180 minutos de ensaio um total de 6,6 $\mathrm{ml}$ de água.

Dentre os revestimentos de recuperação superficial, a argamassa AS-PB apresentou o melhor desempenho à permeabilidade à água líquida, atingindo aos 2880 minutos uma absorção de água interna de apenas 
0,4 ml. Esta baixa absorção de água pela argamassa é positiva para o revestimento pois não afeta de forma substancial as variações dimensionais por umidade e, por consequência, a retração do mesmo. As argamassas colantes, empregadas para correções superficiais, foram as que obtiveram o menor desempenho quanto a permeabilidade à água e poderão sofrer maior influência de fenômenos como o da retração por secagem. Na Tabela 3 apresentam-se o coeficiente de absorção, a absorção de água e a porcentagem de água absorvida pelos revestimentos de argamassa no tempo limite de ensaio (2880 minutos). Os revestimentos AS-PSP, APDO-L e AS-ACIII obtiveram maior absorção de água, chegando, respectivamente, aos 180 minutos de ensaio, a absorções de 1400\%; 946,8\% e 495,3\% superiores à argamassa de referência AP-IND-RM. Todos os demais sistemas empregados apresentaram menor absorção de água em relação ao de referência.

Tabela 3: Coeficiente de absorção de água e absorção de água dos revestimentos de argamassa.

\begin{tabular}{|c|c|c|c|c|c|c|c|c|}
\hline REVESTIMENTO & AS-PSP & AP-DO-L & AS-ACIII & $\begin{array}{c}\text { AP- } \\
\text { IND-RM }\end{array}$ & $\begin{array}{c}\text { AP- } \\
\text { DO-P }\end{array}$ & $\begin{array}{c}\text { AP- } \\
\text { IND-I1 }\end{array}$ & $\begin{array}{c}\text { AP- } \\
\text { IND-I2 }\end{array}$ & AS-PB \\
\hline Tempo total de ensaio (min) & 180 & 180 & 180 & 2880 & 2880 & 2880 & 2880 & 2880 \\
\hline $\begin{array}{l}\text { Volume de água permeada na } \\
\text { superfície - média total }(\mathrm{ml})\end{array}$ & 9,5 & 6,6 & 3,8 & 5,6 & 5,0 & 4,4 & 2,4 & 0,4 \\
\hline $\begin{array}{l}\text { Coeficiente de absorção de } \\
\text { água }\left[\mathrm{kg} /\left(\mathrm{m}^{2} \mathrm{x} \mathrm{h}^{1 / 2}\right)\right]\end{array}$ & 8,9 & 6,2 & 3,5 & 1,3 & 1,2 & 1,0 & 0,6 & 0,1 \\
\hline Absorção de água $\left(\mathrm{kg} / \mathrm{m}^{2}\right)$ & 15,4 & 10,8 & 6,1 & 9,1 & 8,2 & 7,1 & 3,9 & 0,6 \\
\hline $\begin{array}{l}\text { Porcentagem }(\%) \text { de absorção } \\
\text { de água em relação à referên- } \\
\text { cia AP-IND-RM no tempo t }\end{array}$ & 1400 & 946,8 & 495,3 & - & $-10,2$ & $-21,4$ & $-57,5$ & $-93,8$ \\
\hline
\end{tabular}

Na Tabela 4 apresentam-se alguns resultados obtidos por diferentes autores para o ensaio de permeabilidade à água pelo método do cachimbo. Verifica-se pelos seus resultados que a constituição ou os materiais presentes na argamassa influenciam propriedades como a porosidade e conectividade entre os poros, alterando significativamente a capacidade de absorção de água do revestimento.

O maior coeficiente de absorção medido foi para o revestimento em argamassa colante piso sobre piso (AS-PSP) e foi menor apenas que alguns dos resultados obtidos por Alves [26], com valor de $8,9 \mathrm{~kg} /\left(\mathrm{m}^{2} \mathrm{x}\right.$ $\mathrm{h}^{1 / 2}$ ). Por outro lado, revestimentos como o AP-IND-I2 e AS-PB resultaram em coeficientes de absorção menores que os encontrados por qualquer um dos autores apresentados na Tabela 4 , com valores de 0,6 e 0,1 $\mathrm{kg} /\left(\mathrm{m}^{2} \mathrm{x} \mathrm{h}^{1 / 2}\right)$, respectivamente.

Tabela 4: Coeficiente de absorção de água e absorção de água dos revestimentos de argamassa, outros autores.

\begin{tabular}{|c|c|c|c|}
\hline AUTOR & $\begin{array}{l}\text { TIPO DE REVESTIMENTO DE } \\
\text { ARGAMASSA }\end{array}$ & $\begin{array}{l}\text { ABSORÇÃO DE ÁGUA } \\
\text { AOS } 60 \mathrm{~min}\left(\mathrm{~cm}^{3}\right)\end{array}$ & $\begin{array}{c}\text { COEFICIENTE DE } \\
\text { ABSORÇÃO }\left[\mathrm{kg} /\left[\mathrm{m}^{2} \mathrm{xh}^{1 / 2}\right)\right]\end{array}$ \\
\hline \multirow{2}{*}{ Jantsch [25] } & Argamassas estabilizadas de $36 \mathrm{~h}$ & 0,4915 & 0,80 \\
\hline & Argamassas estabilizadas de $72 \mathrm{~h}$ & 2,403 & 3,91 \\
\hline Alves [26] & Argamassa com gravilha & $4,53-19,73$ & $7,40-32,00$ \\
\hline Martinho [27] & $\begin{array}{l}\text { Argamassa com substituição da areia por } \\
\text { mistura de pellets }\end{array}$ & - & $1,29-5,38$ \\
\hline
\end{tabular}

Com relação aos hidrorrepelentes apresentados na Tabela 2, a permeabilidade à água líquida destes revestimentos foi nula em todas as amostras testadas, ou seja, a água não conseguiu penetrar no revestimento, pois existe a formação de uma película superficial impermeável e aderente à base que impede a penetração da água. Durante o ensaio de permeabilidade à água pelo método do cachimbo, notou-se que em alguns pontos houve perda de adesão superficial entre a base antiga e a película aplicada do material impermeabilizante. Esta formação de película garantiria a impermeabilidade à água dos quatro revestimentos hidrorrepelentes testados quando comparados aos de recuperação profunda. Esta perda de adesão comprometeu o desempenho, pois permitiu as transferências gasosas entre os lados interno e externo da parede pela água no estado líquido e de vapor. Portanto, foram observados destacamentos das películas hidrorrepelentes, sendo este um problema para a garantia da estanqueidade da fachada, como mostrado na Figura 6. O revestimento HIDRO1 foi o que apresentou menor destacamento da película, seguido do revestimento HIDRO2. Para os revestimentos 
HIDRO3 e HIDRO4 houve um descolamento total do hidrorrepelente. Verificou-se que as películas formadas apresentaram elasticidade adequada, mas pouca capacidade de adesão à superfície da parede. Como o ensaio foi realizado em dias em que a temperatura era de aproximadamente $24^{\circ} \mathrm{C}$, provavelmente os hidrorrepelentes HIDRO3 e HIDRO4 estavam mais susceptíveis às deformações devido à temperatura superficial, facilitando o descolamento do revestimento de argamassa.

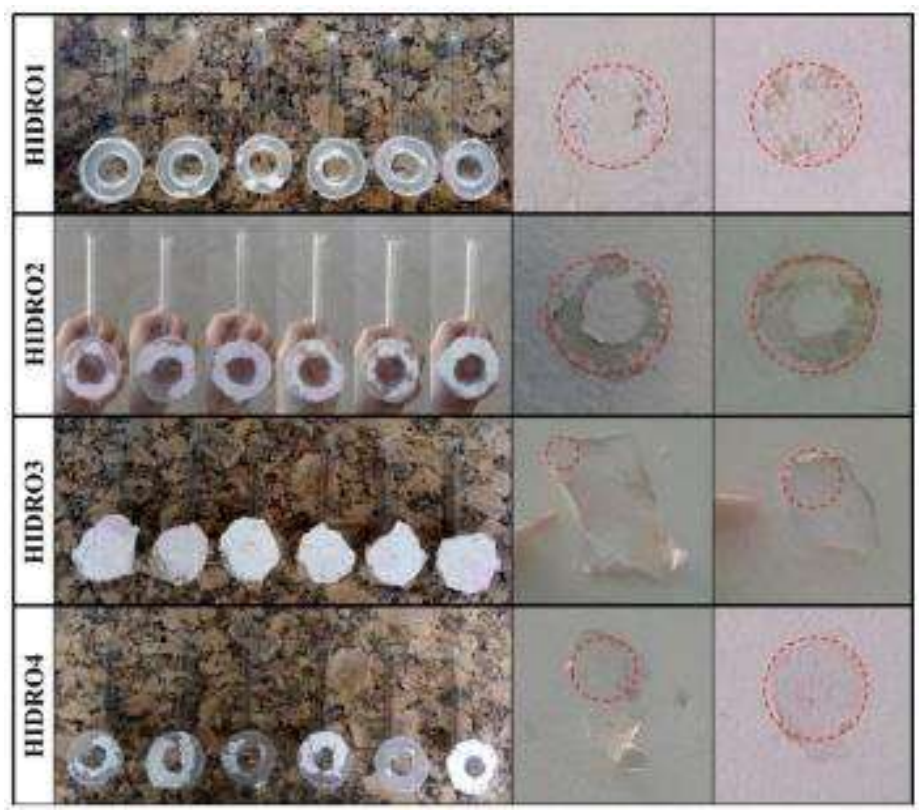

Figura 6: Destacamento da pintura pela retirada dos cachimbos.

Durante o ensaio de permeabilidade à água líquida foram observadas algumas características nos revestimentos como as destacadas na Figura 7, onde é apresentada a área de manchamento provocada pelo fluxo de água ou diâmetro de espalhamento desta no entorno do cachimbo para a parede. Durante os ensaios utilizando o método do cachimbo é interessante observar este fluxo interno de água na fachada, pois quando maior essa área de manchamento, maior o efeito desta na retração superficial por secagem, sendo compatível ao volume total de água permeada na superfície apresentado na Tabela 3. Os revestimentos AP-DO-L e ASACIII apresentaram um diâmetro de manchamento maior em comparação aos demais. Os revestimentos ASPSP, AP-IND-RM e AP-IND-I1 foram semelhantes em relação ao tipo de mancha causada pela permeabilidade. O revestimento AP-DO-P foi o que resultou em um menor manchamento da superfície. Já o revestimento AP-IND-I2, formou eflorescência ou sais solúveis em sua superfície aos 1440 minutos de teste, demonstrando a existência de sais solúveis no revestimento empregado, se mostrando um tipo de revestimento suscetível ao surgimento de manifestações patológicas. Para a argamassa AS-PB, como a quantidade de água penetrada foi muito pequena, não se observou o manchamento da superfície da parede. 


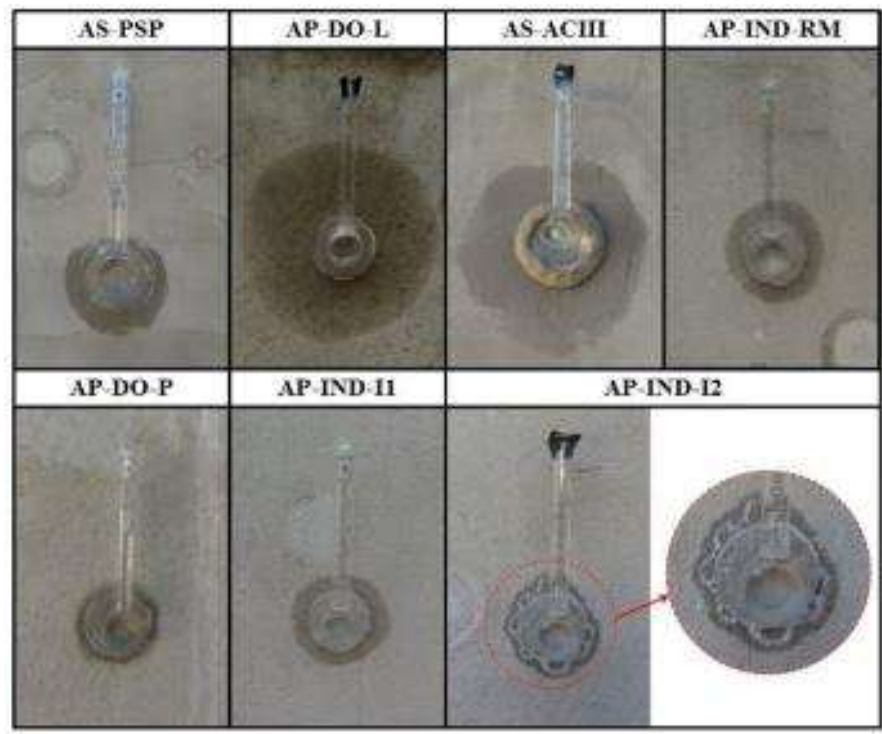

Figura 7: Manchamento nos revestimentos de argamassa no ensaio de permeabilidade à água.

\subsection{Método empírico para avaliação indireta da absorção da água}

Na Figura 8 são apresentadas as imagens do método de ensaio empírico realizado sobre a superfície revestida, com as respectivas visualizações das linhas de quedas de água sobre as argamassas de recuperação profunda. Os revestimentos AP-IND-I1 e AP-DO-L obtiveram quedas de água que escoaram retilineamente ao longo da altura do revestimento. Enquanto os demais revestimentos resultaram em absorção de parte da água durante o escoamento, diminuindo o seu comprimento de queda e aumentando a sua largura pela absorção, rugosidade da superfície e dimensões do agregado. Além disso, destaca-se que podem ter ocorrido microfissuras por retração por secagem do reboco e, por consequência, uma maior absorção de água, com um aumento na largura e abrangência da mancha. 


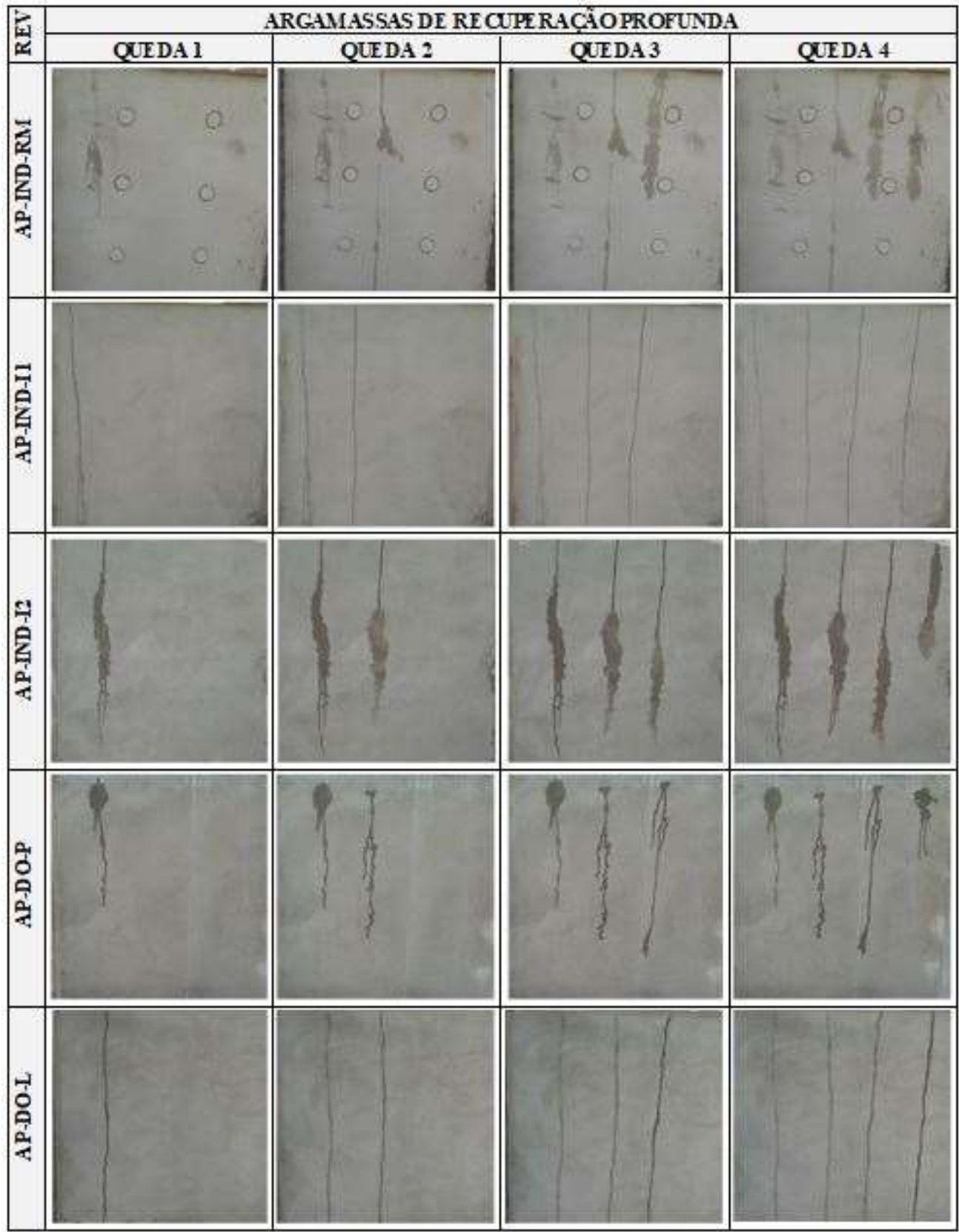

Figura 8: Linhas de queda de água para as argamassas de recuperação profunda.

Na Figura 9, apresentam-se as imagens das quedas de água para os revestimentos de recuperação superficial. No revestimento AS-PB as quedas de água foram retilíneas e não houve espalhamento, mantendo uma largura praticamente igual ao diâmetro da gota aplicada, sendo que a água fluiu pela superfície sem ser absorvida pela camada impermeabilizante, apenas molhando a superfície do revestimento. Quando se empregou a argamassa colante AS-ACIII, verificou-se uma queda de água praticamente retilínea, mas espalhandose lateralmente ao longo da altura pela presença de fissuras internas, presentes no revestimento devido à retração da camada superficial. Já o revestimento AS-PSP apresentou uma alta retração na secagem, com um espalhamento mais concentrado na região de aplicação das gotas. Pela observação visual, verificou-se que a quantidade de água aplicada foi quase inteiramente absorvida pela camada de revestimento superficial, não se mostrando este revestimento como uma barreira impermeável à água. 


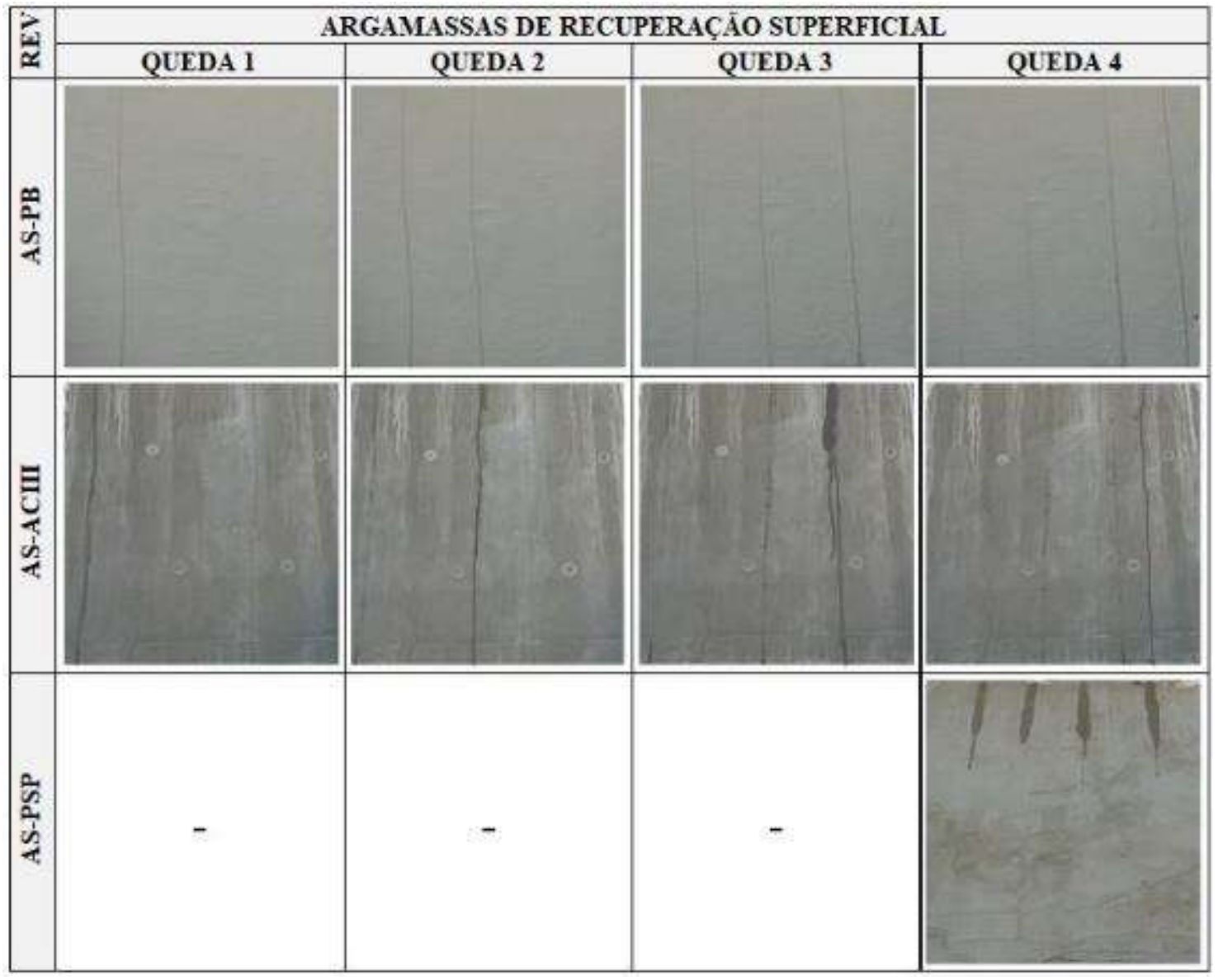

Figura 9: Linhas de queda de água para as argamassas de recuperação superficial.

Na Tabela 5 são apresentadas as alturas de queda ou distância absorvida $(D)$, as larguras de espalhamento da água na superfície dos revestimentos $(\mathrm{lm})$, os tempos de secagem por absorção superficial ou evaporação $(t)$ em que se observou visualmente o desaparecimento das manchas de água no revestimento e a área de manchamento ou espalhamento. Os intervalos de valores apresentados na distância absorvida e na largura de espalhamento de absorção se referem a variação obtida nas medições. O revestimento AS-PB apresentou menor tempo para evaporar da água e foi o revestimento mais impermeável à água líquida, podendo ser interpretado que essa evaporação ocorreu pela baixa absorção do revestimento e pela ação das variações climáticas, portanto, nestas condições foi a mais adequada. Os revestimentos AS-PSP, AP-DO-L e AS-ACIII apresentaram comportamento muito próximo neste ensaio, com um tempo de evaporação da água observado superior ao AS-PB.

Tabela 5: Distância absorvida, largura de espalhamento e tempo médio de evaporação da água nos revestimentos de argamassa.

\begin{tabular}{c|c|c|c|c}
\hline REVESTIMENTO & $\begin{array}{c}\text { DISTÂNCIA } \\
\text { ABSORVIDA } \\
\text { D (cm) }\end{array}$ & $\begin{array}{c}\text { LARGURA DE } \\
\text { ESPALHAMENTO DE } \\
\text { ABSORÇÃO } \mathbf{~ m ~} \mathbf{( c m})\end{array}$ & $\begin{array}{c}\text { ÁREA DE ESPALHAMENTO } \\
\text { DA ÁGUA ABSORVIDA } \\
\left.\mathbf{( c m}^{2}\right)\end{array}$ & $\begin{array}{c}\text { TEMPO MÉDIO DE } \\
\text { EVAPORAÇÃO } \\
\mathbf{t}(\mathbf{m i n})\end{array}$ \\
\hline AS-PB & 100 & 0,5 & 65 & $00: 14: 26$ \\
\hline AS-PSP & $35-45$ & $0,5-5$ & 51 & $00: 19: 03$ \\
\hline AP-DO-L & 100 & $0,9-2,5$ & 126 & $00: 20: 10$ \\
\hline AS-ACIII & 100 & $0,3-2,5$ & 82 & $00: 24: 14$ \\
\hline AP-IND-I2 & $54-100$ & $1-7,5$ & 314 & $00: 27: 23$ \\
\hline AP-IND-I1 & 100 & $0,4-0,8$ & 71 & $00: 31: 02$ \\
\hline AP-DO-P & $28-74$ & $0,7-8$ & 142 & $00: 38: 44$ \\
\hline AP-IND-RM & $49-100$ & $0,8-6,5$ & 141 & $00: 39: 26$
\end{tabular}


Quanto aos revestimentos hidrorrepelentes, todas as amostras testadas não absorveram a água vertida pelo conta-gotas, ou seja, a água quando fluiu pela superfície do revestimento não foi absorvida pelo mesmo. Ademais, como este ensaio foi idealizado pelos autores deste trabalho, não se encontrou na bibliografia corrente resultados de estudos que pudessem permitir comparações.

\subsection{Termografia infravermelha}

De posse dos valores de emissividade de cada material, foram registradas as imagens termográficas dos revestimentos aplicados. Na Figura 10 são apresentadas as imagens dos ensaios de termografia para os revestimentos hidrorrepelentes, observando que na condição "seco" as temperaturas superficiais dos revestimentos foram muito próximas nas três medições, aumentando de acordo com o crescimento da temperatura ambiente. O mesmo fato ocorreu na condição "úmido" do ensaio.

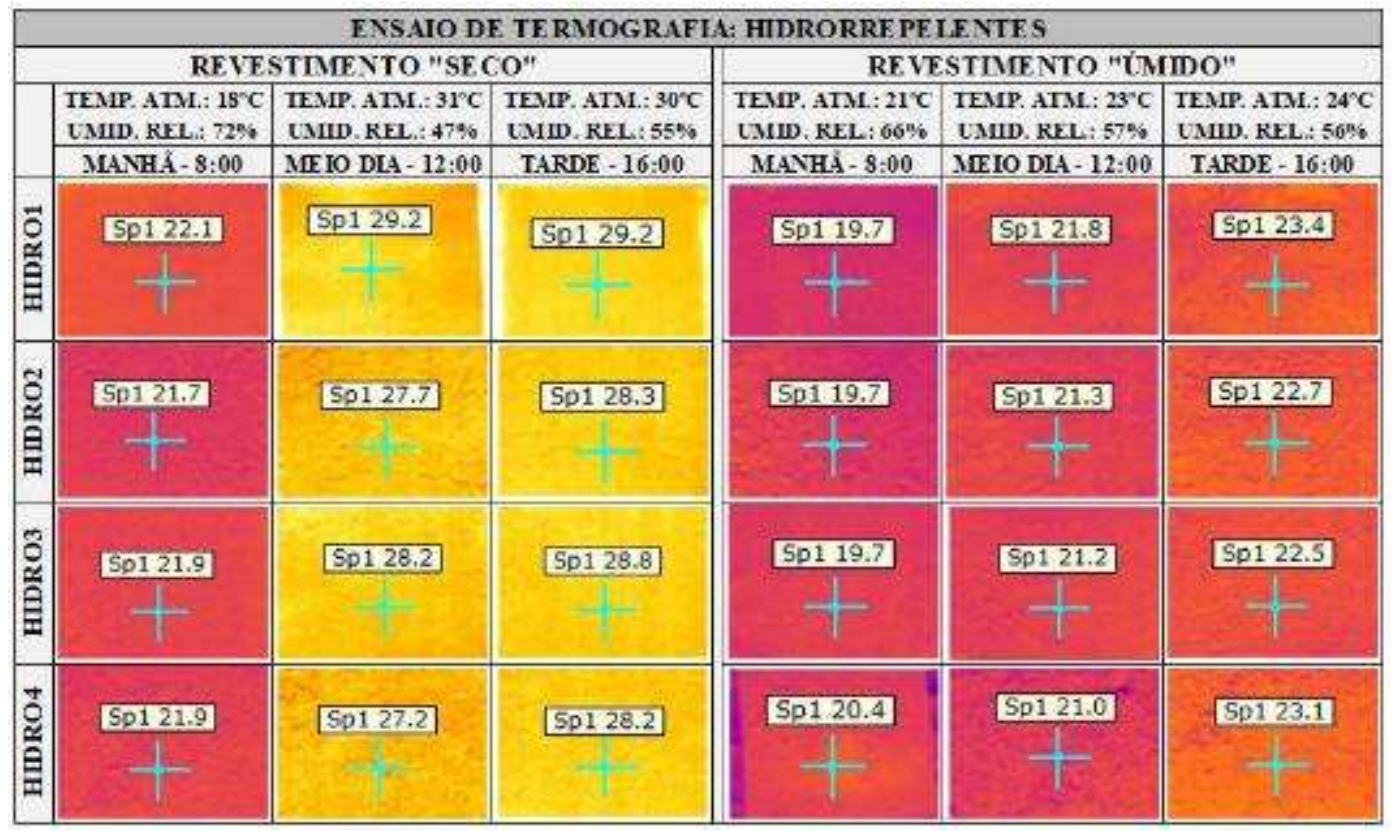

Figura 10: Resultados do ensaio de termografia para os revestimentos hidrorrepelentes.

Já na Figura 11 são mostrados os resultados do ensaio de termografia para os revestimentos de argamassa de recuperação superficial sob a condição "seco", onde foram obtidas temperaturas superficiais muito próximas nas três medições, modificando-se conforme variava a temperatura ambiente. Na condição "úmido" de ensaio, se observa, praticamente, o mesmo comportamento da condição "seco", apenas a argamassa de recuperação profunda AP-DO-L exibiu uma pequena diferença nas três medições. A temperatura superficial de AP-DO-L foi em torno de $2{ }^{\circ} \mathrm{C}$ inferior às demais argamassas, demostrando que, possivelmente, havia maior quantidade de água naturalmente absorvida e retida na estrutura interna da argamassa. 


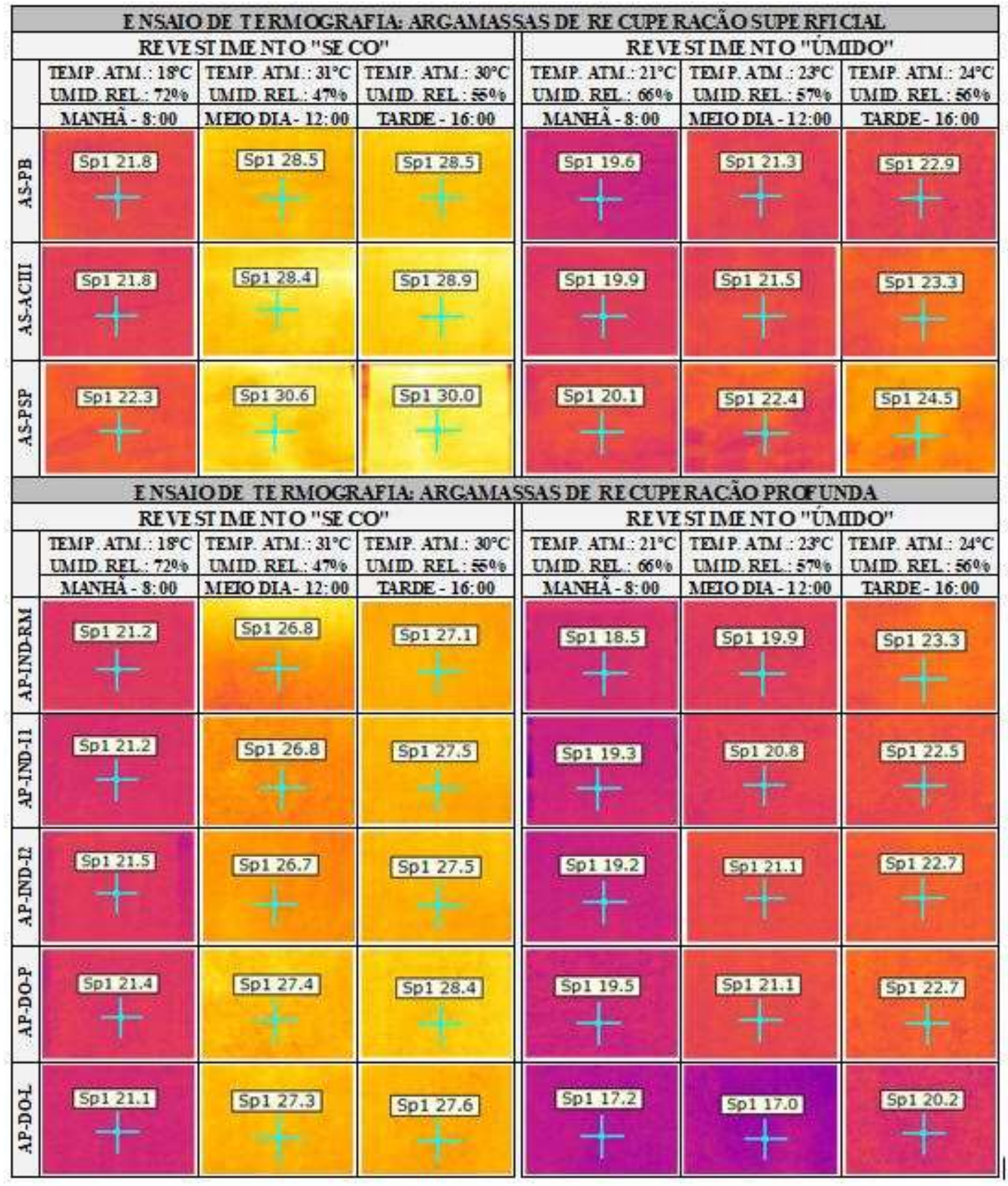

Figura 11: Resultados do ensaio de termografia para os revestimentos em argamassa.

Como a fachada da parede avaliada tem orientação sul, pôde-se verificar que as temperaturas superficiais medidas nos revestimentos de recuperação profunda, superficial e hidrorrepelentes, foram muito semelhantes, com gradientes térmicos próximos e um erro relativo nos diferentes períodos de medição (manhã, meio-dia e tarde) de aproximadamente $6^{\circ} \mathrm{C}$. Neste caso, a condição térmica não foi suficientemente diferente para propiciar o surgimento de fissuras por expansões e retrações térmicas. Observa-se na Figura 12 a diferença exibida pelo revestimento de argamassa AP-DO-L na condição "úmido" de ensaio. Na imagem termográfica obtida no período da manhã, há uma grande mancha no revestimento AP-DO-L identificável a partir da diferença do gradiente de cores, evidenciando uma provável existência de umidade interna no revestimento. Com o aumento da temperatura ambiente ao longo do dia, houve a evaporação da água, ocorrendo de maneira mais significativa na região das bordas externas em direção ao centro do revestimento. As manchas presentes no revestimento HIDRO3 na Figura 12 são devido ao descolamento da pintura ocorrido no ensaio de permeabilidade à água líquida pelo método do cachimbo. 


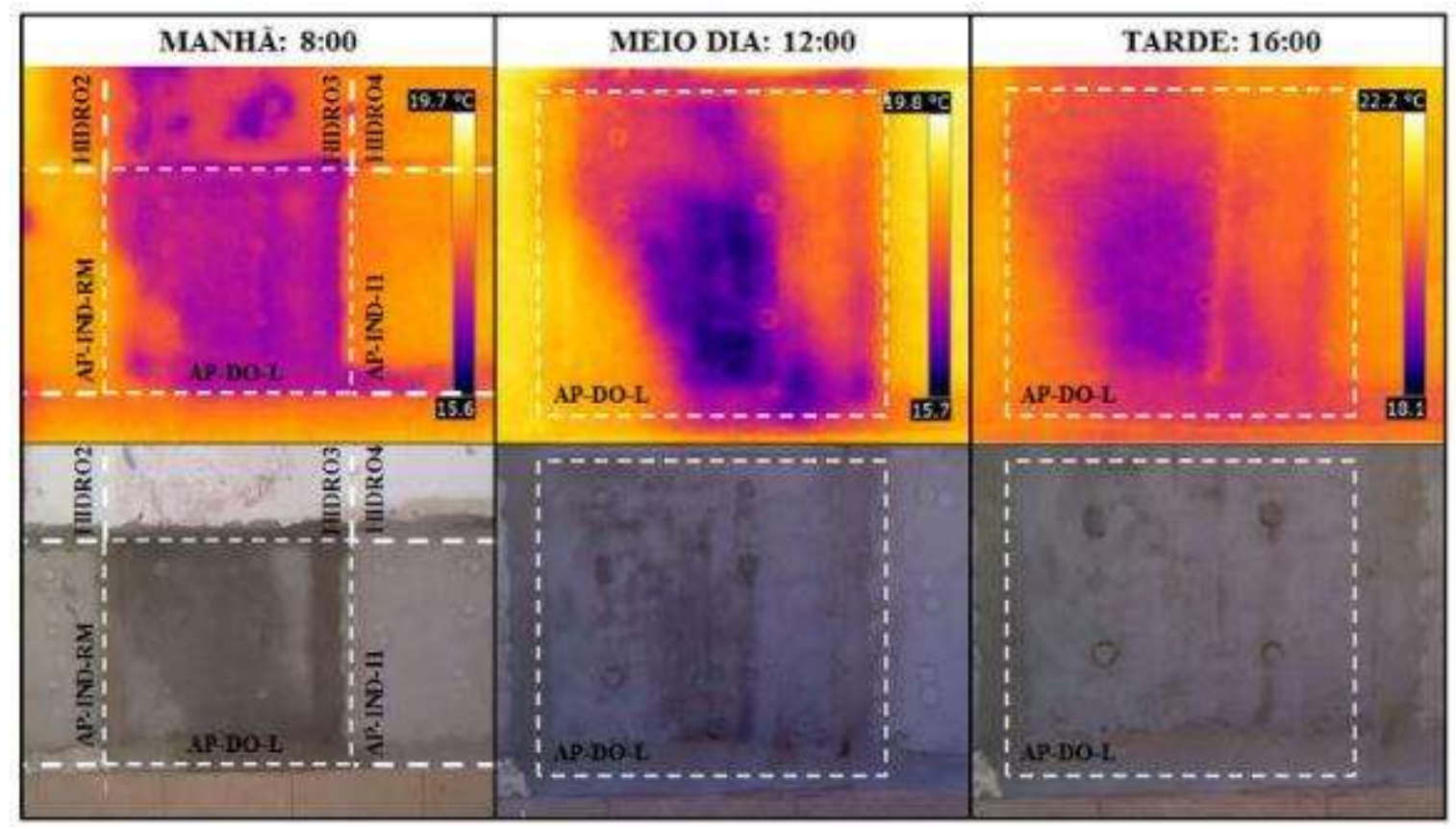

Figura 12: Resultados do ensaio de termografia no revestimento de argamassa AP-DO-L.

A utilização da termografia infravermelha para a identificação de umidade em edificações tem se mostrado adequada e já foi empregada em diversos estudos, pois pelo gradiente de temperatura se consegue detectar com facilidade a presença da umidade a partir das diferenças de cores no termograma. No entanto, esse tipo de avaliação não permite verificar o efeito em relação à profundidade. Na Figura 13 apresentam-se alguns autores que utilizaram esta técnica na detecção de focos de umidade e outras manifestações patológicas, nos quais apontaram o ensaio como apropriado para estas situações fornecendo maiores informações do que apenas inspeção visual. 


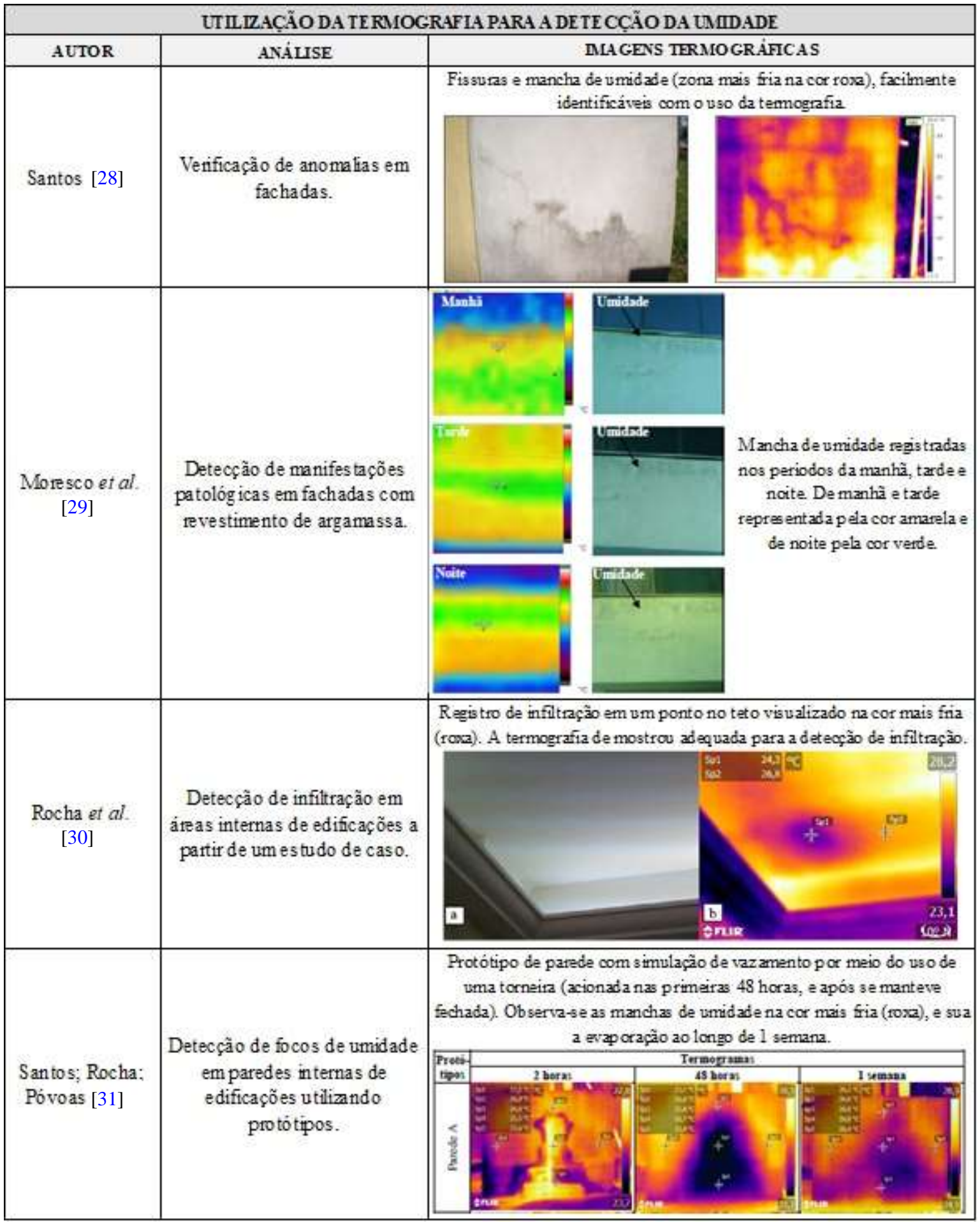

Figura 13: Resultados do ensaio de termografia de diferentes autores.

\subsection{Resistência de aderência à tração}

A resistência de aderência das argamassas de recuperação profunda é apresentada na Tabela 6. Nenhum revestimento alcançou a resistência mínima de $0,30 \mathrm{MPa}$ para revestimentos de fachada, de acordo com a exigência da NBR 13749 [32]. Os tijolos cerâmicos maciços do substrato, de superfície lisa, sem rugosidades ou saliências, prejudicaram a aderência com o revestimento de recuperação. Por isso, nestes casos, existiria a necessidade de aumentar a adesão por meio, por exemplo, da aplicação de uma resina sintética de alto desempenho para proporcionar uma maior aderência das argamassas de recuperação ao substrato. O modo de ruptura das argamassas industrializadas foi na interface substrato/chapisco (AP-IND-RM) ou na interface substrato/revestimento (AP-IND-I1 e AP-IND-I2), ocorrendo de forma adesiva. As argamassas dosadas em 
obra romperam de maneira coesiva na argamassa para AP-DO-P e no chapisco para AP-DO-L. Na Tabela 7 estão expostos os resultados da resistência de aderência à tração para as argamassas de recuperação superficial. A resistência de no mínimo de 8 corpos de prova também não alcançou o valor mínimo estabelecido pela norma NBR 13749 [32], de 0,30 MPa para paredes externas, mas houve um alto valor de coeficiente de variação. A ruptura ocorreu na argamassa de revestimento existente, de maneira coesiva.

Tabela 6: Resultado dos ensaios de resistência de aderência à tração das argamassas de recuperação profunda.

\begin{tabular}{|c|c|c|c|c|c|c|c|c|c|c|c|c|}
\hline \multirow{2}{*}{ 足 } & \multirow{2}{*}{ 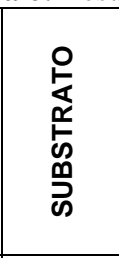 } & \multicolumn{2}{|c|}{ CHAPISCO } & \multicolumn{4}{|c|}{$\begin{array}{l}\text { LOCAL DO ENSAIO } \\
(\%)\end{array}$} & \multirow{2}{*}{ 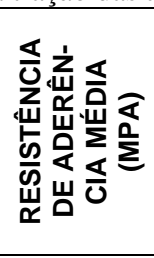 } & \multirow{2}{*}{ 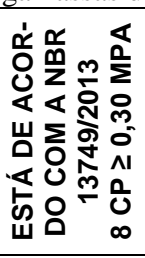 } & \multirow{2}{*}{ 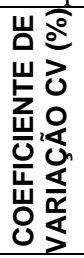 } & \multirow{2}{*}{ 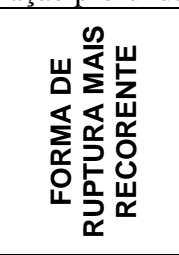 } & \multirow{2}{*}{ 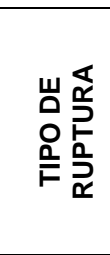 } \\
\hline & & 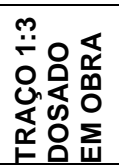 & 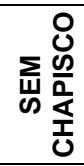 & $\begin{array}{l}\text { 염 } \\
\text { 올 } \\
\text { F }\end{array}$ & $\begin{array}{l}\text { I } \\
\text { 点 } \\
⿱ 3\end{array}$ & 点 & 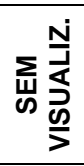 & & & & & \\
\hline 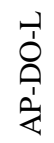 & $\begin{array}{c}\text { Tijolo } \\
\text { Maciço }\end{array}$ & $\mathrm{x}$ & & 44 & 7 & 3 & 46 & 0,24 & Não & 40 & $\begin{array}{c}\text { Chapisco } \\
51 \%\end{array}$ & Coesiva \\
\hline $\begin{array}{l}\sum_{1} \\
\text { 竞 } \\
\vdots \\
\frac{1}{4}\end{array}$ & $\begin{array}{l}\text { Tijolo } \\
\text { Maciço }\end{array}$ & $\mathrm{x}$ & & 58 & 12 & 1 & 30 & 0,21 & Não & 42 & $\begin{array}{c}\text { Sub/Chap } \\
63 \%\end{array}$ & Adesiva \\
\hline $\begin{array}{l}\overline{1} \\
\dot{2} \\
\text { 妾 }\end{array}$ & $\begin{array}{l}\text { Tijolo } \\
\text { Maciço }\end{array}$ & & $\mathrm{x}$ & 70 & 13 & 13 & 5 & 0,22 & Não & 56 & $\begin{array}{c}\text { Sub/Arg Rev } \\
80 \%\end{array}$ & Adesiva \\
\hline $\begin{array}{l}0^{\prime} \\
0 \\
a^{\prime} \\
\dot{4}\end{array}$ & $\begin{array}{c}\text { Tijolo } \\
\text { Maciço }\end{array}$ & $\mathrm{x}$ & & 23 & 6 & 5 & 66 & 0,14 & Não & 39 & $\begin{array}{c}\text { Arg Rev } \\
58 \%\end{array}$ & Coesiva \\
\hline 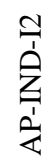 & $\begin{array}{l}\text { Tijolo } \\
\text { Maciço }\end{array}$ & & $\mathrm{x}$ & 65 & 18 & 10 & 7 & 0,07 & Não & 109 & $\begin{array}{c}\text { Sub/Arg Rev } \\
67 \%\end{array}$ & Adesiva \\
\hline
\end{tabular}

Tabela 7: Resultado do ensaio de resistência de aderência à tração das argamassas de recuperação superficial.

\begin{tabular}{|c|c|c|c|c|c|c|}
\hline 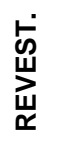 & SUBSTRATO & $\begin{array}{c}\text { ESTÁ DE } \\
\text { ACORDO COM A } \\
\text { NBR 13749:2013 } \\
\geq 0,30 \mathrm{MPa}\end{array}$ & $\begin{array}{c}\text { RESISTÊNCIA DE } \\
\text { ADERÉNCIA } \\
\text { MÉDIA (MPa) }\end{array}$ & $\begin{array}{l}\text { COEFICIENTE } \\
\text { DE VARIAÇÃO } \\
\text { CV (\%) }\end{array}$ & $\begin{array}{l}\text { FORMA DE } \\
\text { RUPTURA }\end{array}$ & $\begin{array}{l}\text { TIPO DE } \\
\text { RUPTURA }\end{array}$ \\
\hline 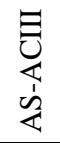 & $\begin{array}{l}\text { Argamassa de reves- } \\
\text { timento existente }\end{array}$ & Não & 0,15 & 70 & $\begin{array}{c}\text { Arg. rev. } \\
100 \%\end{array}$ & Coesiva \\
\hline$\frac{\infty}{2}$ & $\begin{array}{l}\text { Argamassa de reves- } \\
\text { timento existente }\end{array}$ & Não & 0,08 & 83 & $\begin{array}{c}\text { Arg. rev. } \\
100 \%\end{array}$ & Coesiva \\
\hline $\begin{array}{l}0 \\
\infty \\
\sum_{1}^{1} \\
4\end{array}$ & $\begin{array}{l}\text { Argamassa de reves- } \\
\text { timento existente }\end{array}$ & Não & 0,08 & 60 & $\begin{array}{c}\text { Arg. rev. } \\
100 \%\end{array}$ & Coesiva \\
\hline
\end{tabular}

Na Figura 14 pode ser visualizado que os revestimentos de argamassa industrializada de recuperação profunda AP-IND-RM, AP-IND-I1 e AP-IND-I2 não obtiveram resistência de aderência suficiente e resultaram em ruptura adesiva, possibilitando que o revestimento possa ao longo do tempo desplacar devido a perda da aderência superficial. Os revestimentos de recuperação profunda AP-DO-L e AP-DO-P apresentaram ruptura coesiva, mas também não atingiram a resistência mínima de aderência exigida pela norma NBR 13749 [32]. Da mesma forma que as argamassas de recuperação superficial, romperam de forma coesiva no substrato. 


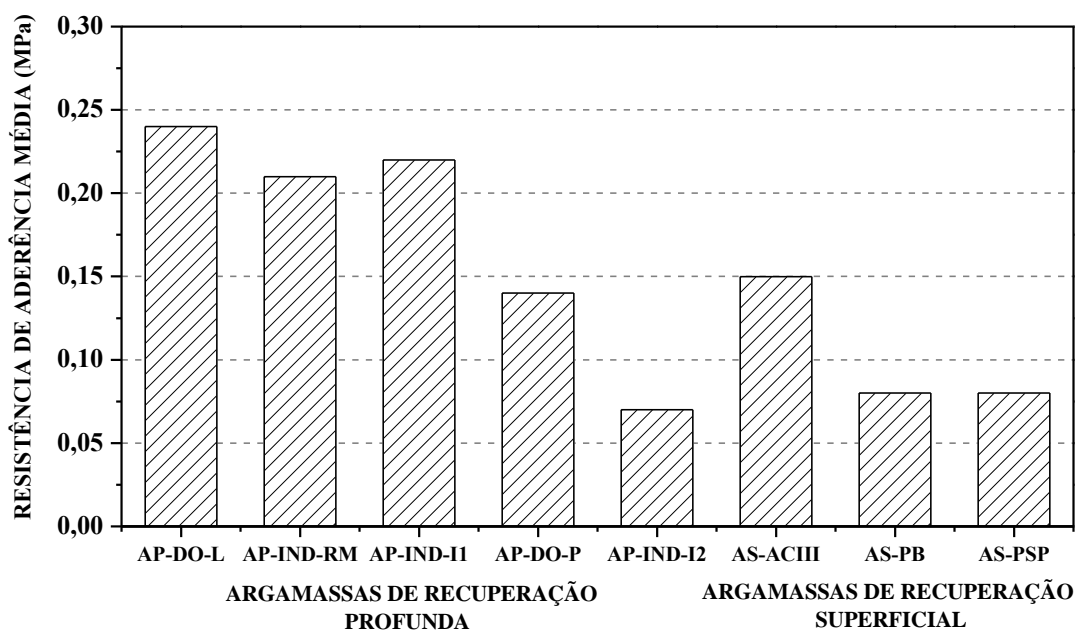

Figura 14: Resistência de aderência à tração média e coeficiente de variação das argamassas.

As rupturas adesivas sucedidas na interface do substrato podem ter sido influenciadas por algum defeito na remoção do reboco antigo. Para as argamassas industrializadas de recuperação profunda AP-IND-I1 e AP-IND-I2 a ruptura também pode ter ocorrido pela ausência de chapisco.

Pelo motivo deste trabalho utilizar revestimentos específicos disponíveis no mercado da construção civil, não se encontrou autores que apresentassem resultados de resistência de aderência para estas mesmas combinações de revestimentos. Contudo, na Tabela 8 são apresentados alguns resultados de outros autores para este mesmo tipo de ensaio, mas com outros revestimentos de argamassa. A partir disso, é possível identificar que a resistência de aderência à tração é variável e completamente dependente das características/tipologia do substrato, bem como, do próprio revestimento, sendo singular para cada situação.

Tabela 8: Resultado do ensaio de resistência de aderência à tração das argamassas, outros autores.

\begin{tabular}{|c|c|c|c|c|}
\hline AUTOR & TIPO DE REVESTIMENTO DE ARGAMASSA & $\begin{array}{c}\begin{array}{c}\text { RESISTÊNCIA } \\
\text { DE ADERÊNCIA } \\
(\mathrm{MPa})\end{array} \\
\end{array}$ & $\begin{array}{c}\text { VALORES ACEITÁ- } \\
\text { VEIS PELA NORMA } \\
\text { NBR 13749 [32] } \\
\end{array}$ & $\begin{array}{l}\text { TIPO DE } \\
\text { RUPTU- } \\
\text { RA } \\
\end{array}$ \\
\hline \multirow{2}{*}{ Jantsch [25] } & Argamassa estabilizada de $36 \mathrm{~h}$ & 0,719 & $\geq 0,30 \mathrm{MPa}$ & $\begin{array}{l}\text { Superfici- } \\
\text { al }\end{array}$ \\
\hline & Argamassa estabilizada de $72 \mathrm{~h}$ & 0,057 & $<0,2 \mathrm{MPa}$ & Coesiva \\
\hline \multirow{3}{*}{$\begin{array}{l}\text { Passos e Cara- } \\
\quad \text { sek [33] }\end{array}$} & Argamassa convencional traço 1:1:6 & 0,210 & \multirow{3}{*}{$\geq 0,30 \mathrm{MPa}$} & Coesiva \\
\hline & Argamassa com $80 \%$ de EPS & 0,050 & & Coesiva \\
\hline & Argamassa com $80 \%$ de EPS & 0,030 & & Coesiva \\
\hline \multirow{3}{*}{$\begin{array}{l}\text { Albuquerque } \\
\text { [34] }\end{array}$} & $\begin{array}{c}\text { Argamassa convencional traço } 1: 1: 5: 1,33 \\
\text { (cimento Portland branco: cal hidratada: areia: } \\
\text { água) }\end{array}$ & 0,360 & \multirow{3}{*}{$\geq 0,30 \mathrm{MPa}$} & \multirow{3}{*}{$\begin{array}{l}\text { Não indi- } \\
\text { ca }\end{array}$} \\
\hline & $\begin{array}{c}\text { Argamassa com adição 5\% resíduo dióxido de } \\
\text { titânio }\end{array}$ & 0,350 & & \\
\hline & $\begin{array}{c}\text { Argamassa com adição } 10 \text { e } 15 \% \text { resíduo dióxi- } \\
\text { do de titânio }\end{array}$ & 0,370 & & \\
\hline
\end{tabular}

Conforme a norma francesa NF EN 1015-21 [35] e o relatório 427/05 [36] do LNEC de Portugal, em revestimentos externos a resistência de aderência mínima deve ser igual ou superior a 0,30 MPa somente quando as rupturas se apresentarem de forma adesiva, ou seja, nas interfaces, pois são os locais mais perigosos e consequentemente de maior potencial para o surgimentos de manifestações patológicas. Desta forma, para este trabalho por mais que os revestimentos não tenham atingido o valor mínimo estabelecido pela nor- 
ma, a maioria das rupturas foram coesivas. Somente as argamassas industrializadas de recuperação profundas romperam de maneira adesiva.

\section{CONCLUSÕES}

Este trabalhou avaliou o desempenho de estanqueidade à água de revestimentos argamassados industrializados e dosados em obra com aditivos impermeabilizantes, bem como, de revestimentos hidrorrepelentes formadores de película. A partir dos resultados obtidos, pode-se concluir:

- As argamassas AS-PB e AP-IND-I2 foram as que mais impediram a entrada de água no revestimento, principalmente a AS-PB, quando avaliadas pelo ensaio de permeabilidade à água líquida por meio do método do cachimbo, provavelmente devido a presença das resinas e aditivos impermeabilizantes em suas composições.

- As argamassas colantes e AP-DO-L apresentaram os piores desempenhos em relação a estanqueidade a água e de aderência à tração, não sendo recomendado o seu emprego neste tipo de fachada com a finalidade buscada neste estudo.

- Os revestimentos hidrorrepelentes bloquearam totalmente a entrada de água no revestimento devido a formação de uma película superficial, revelando o seu alto desempenho quanto a estanqueidade à água, contudo, apresentaram pouca aderência com o revestimento da base, ocasionando seu destacamento da superfície podendo resultar em soluções pouco duráveis.

- Pôde-se verificar que as temperaturas superficiais medidas nos revestimentos de recuperação profunda, superficial e hidrorrepelentes, foram muito semelhantes, com gradientes térmicos próximos e um erro relativo nos diferentes períodos de medição (manhã, meio-dia e tarde) de aproximadamente $6{ }^{\circ} \mathrm{C}$, ou seja, a condição térmica não foi suficientemente diferente para que propiciasse o surgimento de fissuras por expansões e retrações térmicas.

- O ensaio de resistência de aderência à tração realizado em todos os revestimentos de argamassa não apresentou resultados satisfatórios, uma vez que nenhum dos revestimentos atingiu o mínimo estabelecido pela norma NBR 13749 [32]. Os tijolos cerâmicos maciços, base da aplicação, por serem lisos, sem rugosidades ou saliências, prejudicaram a aderência entre o substrato e o revestimento de recuperação. Por isso, nestes casos, existe a necessidade de aumentar a adesão por meio da aplicação de uma resina sintética de alto desempenho para proporcionar uma maior aderência das argamassas de recuperação ao substrato. De qualquer forma, o revestimento que apresentou maior resistência de aderência foi a argamassa AP-DO-L, seguido da referência AP-IND-RM e AP-IND-I1. Já o revestimento AP-IND-I2, que apresentou um desempenho satisfatório diante da estanqueidade à água, apresentou uma resistência de aderência muito baixa, provavelmente influenciada pela ausência do chapisco. Conclui-se, então, que para cada tipo de intervenção é necessária a avaliação prévia do potencial de aderência do substrato ao material de recuperação empregado por meio de ensaios laboratoriais a fim de atender o estabelecido nos padrões normativos.

Diante do exposto, no geral, os resultados demonstraram que os revestimentos hidrorrepelentes possuem maior estanqueidade à água do que os revestimentos de argamassa analisados, logo se sugere a sua utilização para a recuperação de fachadas degradas pela umidade. Os hidrorrepelentes podem também ser utilizados como uma última camada no sistema de revestimento de fachadas. Contudo, anteriormente é necessária uma análise das condições da base do revestimento já existente para que a durabilidade do sistema de revestimento não seja prejudicada pela falta de aderência entre as camadas.

\section{BIBLIOGRAFIA}

[1] ASSOCIAÇÃO BRASILEIRA DE NORMAS TÉCNICAS. NBR 15575-1. Edificações habitacionais Desempenho. Parte 1: Requisitos gerais. Rio de Janeiro, 2013.

[2] DUARTE, R., FLORES-COLEN, I., BRITO, J., "In situ testing techniques for evaluation of water penetration in rendered facades - the portable moisture meter and Karsten tube", In: International Conference on Durability of Building Materials and Components, 2011, Porto-Portugal, XII DBMC.

[3] BAUER, E., SILVA, M. N. B., ZANONI, V. A. G. "Mensuração da degradação e vida útil em fachadas". In: XI Simpósio Brasileiro de Tecnologia das Argamassas, 2015, Porto Alegre.

[4] MADUREIRA, S., FLORES-COLEN, I., BRITO, J., et al., "Maintenance planning of facades in current buildings", Construction and Building Materials, v. 147, pp. 790-802, 2017. 
[5] SALOMÃO, M. C. F., Estudo da estrutura das argamassas de revestimento e sua influência nas propriedades de transporte de água, Tese de D.Sc., Universidade de Brasília, DF, Brasil, 2016.

[6] BALL, R. J., ALLEN, G. C., "The measurement of water transport in porous materials using impedance spectroscopy", Journal of physics D: Applied physics, v. 43, n. 10, 2010.

[7] DELGADO, J. M. P. Q., FREITAS, V. P., GUIMARÃES, A. S., "Water movement in building walls: interfaces influence on the moisture flux", Heat Mass Transfer, v. 52, pp. 2415-2422, 2016.

[8] HALL, C., KALIMERIS, A. N., "Water Movement in Porous Building Materials - V. Absorption and Shedding of Rain by Building Surfaces", Building and Environment, v. 17, n. 4, pp. 257-262, 1982.

[9] HALL, C., HOFF, W. D., NIXON, M. R., "Water Movement in Porous Building Materials - VI. Evaporation and Drying in Brick and Block Materials", Building and Environment, v. 19, n. 1, pp. 13-20, 1984.

[10] GONÇALVES, T. D., BRITO, V., MUSACCHI, J., "The whole and the parts: Can lime coatings enhance the drying of salt laden materials", Construction and Building Materials, v. 57, pp. 179-189, 2014.

[11] CHEW, M. Y. L., TAN, P. P., "Facade staining arising from design features", Construction and Building Material, v. 17, pp. 181-187, 2013.

[12] GE, H., CHIU, V., STATHOPOULOS, T., et al., "Improved assessment of wind-driven rain on building façade based on ISO standard with high-resolution on-site weather data", Journal of Wind Engineering \& Industrial Aerodynamics, v. 176, pp. 183-196, 2018.

[13] ASSOCIAÇÃO BRASILEIRA DE NORMAS TÉCNICAS. NBR 15575-4. Edificações habitacionais Desempenho. Parte 4: Requisitos para os sistemas de vedações verticais internas e externas - SVVIE. Rio de Janeiro, 2013.

[14] OLSSON, L., "Rain resistance of façades with façade details: A summary of three field and laboratory studies", Journal of Building Physics, v. 41, pp. 521-532, 2018.

[15] PEREIRA, C., BRITO, J., SILVESTRE, J. D., "Contribution of humidity to the degradation of façade claddings in current buildings", Engineering Failure Analysis, v. 90, pp. 103-115, 2018.

[16] GASPAR, P. L., BRITO, J., "Durabilidade, estados limite e vida útil de reboco em fachadas". In: III Congresso Nacional de Argamassas de construção, 2010, Lisboa.

[17] ASSOCIAÇÃO BRASILEIRA DE NORMAS TÉCNICAS. NBR 9575. Impermeabilização - Seleção $e$ projeto. Rio de Janeiro, 2010.

[18] CENTRE SCIENTIFIQUE ET TECHNIQUE DE LA CONSTRUTION. Nota Informativa Técnica NIT 197: Limpeza de fachadas. Bruxelles, 1995.

[19] Reunion internationale des laboratoires d'essais et de recherches sur les materiaux et les constructions. RILEM II.4. Measurement of water absorption under low pressure. 1987. Lawrence.

[20] FLORES-COLEN, I., Metodologia de Avaliação do desempenho em serviço de fachadas rebocadas na óptica da manutenção predictiva, Dissertação de M.Sc., Instituto Superior Técnico, Lisboa, Portugal, 2009.

[21] INTERNATIONAL STANDARD. ISO. ISO 15148.Hygrothermal performance of building materials and products - Determination of water absorption coefficient by partial immersion. Switzerland, 2002.

[22] EUROPEAN COMMITTEE FOR STANDARDIZATION. EN 13187.Thermal performance of buildings, qualitative detection of thermal irregularities in building envelopes - Infrared method. Brussels, 1999.

[23] INTERNATIONAL STANDARD. ISO. ISO 18434-1. Condition monitoring and diagnosis of machines - Thermography - Part 1: General procedures. Geneva. 2008.

[24] ASSOCIAÇÃO BRASILEIRA DE NORMAS TÉCNICAS. NBR 13528. Revestimento de paredes $e$ tetos de argamassas inorgânicas - Determinação da resistência de aderência à tração. Rio de Janeiro, 2010.

[25] JANTSCH, A. C. A., "Análise do desempenho de argamassas estabilizadas submetidas a tratamento superficial com aditivos cristalizantes", Dissertação de M.Sc., Universidade Federal de Santa Maria, RS, Brasil, 2015.

[26] ALVES, R. M. C., "Argamassas no Arquipélago da Madeira: caracterização da "Brita Lavada", Dissertação de M.Sc., Universidade Nova de Lisboa, Portugal, 2016.

[27] MARTINHO, P. A. G., "Análise do comportamento de argamassas com a incorporação de "pellets" de madeira”, Dissertação de M.Sc., Universidade Nova de Lisboa, Portugal, 2017.

[28] SANTOS, L. M. A. A., "Análise in-situ do comportamento mecânico de argamassas de revestimento de fachadas”, Dissertação de M.Sc., Universidade Técnica de Lisboa, Portugal, 2012. 
[29] MORESCO, J., BORDIN, F., VERONEZ, M. R., et al., "Termografia infravermelha na detecção de manifestações patológicas em fachadas com revestimento argamassado", In: $11^{\circ}$ Congresso Internacional sobre Patologia e Recuperação de Estruturas, São Leopoldo-Brasil, XI CINPAR, 2015.

[30] ROCHA, J. H. A., SANTOS, C. F., OLIVEIRA, J. B., et al., "Detecção de infiltração em áreas internas de edificações com termografia infravermelha: estudo de caso", Ambiente Construído, v. 18, pp. 329-340, 2018.

[31] SANTOS, C. F., ROCHA, J. H. A., PÓVOAS, Y. V., "Utilização da termografia infravermelha para detecção de focos de umidade em paredes internas de edificações”, Ambiente Construído, v. 19, pp. 105-127, 2019.

[32] ASSOCIAÇÃO BRASILEIRA DE NORMAS TÉCNICAS. NBR 13749. Revestimento de paredes e tetos de argamassas inorgânicas - Especificação. Rio de Janeiro, 2013.

[33] PASSOS, P. M., CARASEK, H., “Argamassas com resíduos para revestimento isolante térmico de parede pré-moldada de concreto”, Cerâmica, v. 64, pp. 577-588, 2018.

[34] ALBUQUERQUE, D. D. M., “Avaliação da influência do resíduo proveniente da produção do dióxido de titânio (MNR) nas propriedades das argamassas de revestimento e na sua capacidade fotocatalítica", Dissertação de M.Sc., Universidade Federal da Bahia, BA, Brasil, 2018.

[35] ASSOCIATION FRANCAISE DE NORMALISATION. NF EN 1015-21. Methods Of Test For Mortar For Masonry - Part 21: Determination Of The Compatibility Of One-coat Rendering Mortars With Substrates. France, 2003.

[36] LABORATÓRIO NACIONAL DE ENGENHARIA CIVIL. RELATÓRIO 427/05. Regras para concessão de documentos de aplicação a revestimentos pré-doseados de ligante mineral com base em cimento para paredes. Lisboa, 2005.

\section{ORCID}

Thiana Dias Hermann

Gihad Mohamad

Almir Barros da Silva Santos Neto

Rogério Cattelan Antocheves de Lima

André Lübeck https://orcid.org/0000-0002-0615-6327

https://orcid.org/0000-0002-6380-364X

https://orcid.org/0000-0001-7306-5313

https://orcid.org/0000-0001-6622-2210

https://orcid.org/0000-0001-5772-9933 